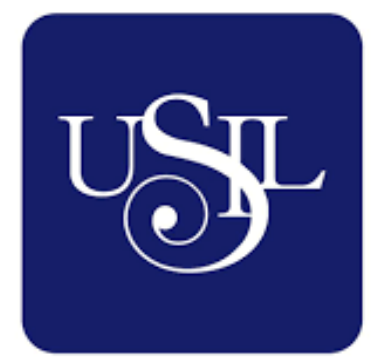

UNIVERSIDAD

SAN IGNACIO

DE LOYOLA

FACULTAD DE HUMANIDADES

Carrera de Psicología

\title{
BIENESTAR PSICOLÓGICO Y ENGAGEMENT EN COLABORADORES DE UNA UNIVERSIDAD PRIVADA DE LIMA METROPOLITANA
}

\author{
Tesis para optar el Título Profesional de \\ Licenciado en Psicología
}

\section{KERLY STEFANNY DURAN QUISPE (0000-0002-7960-8857)}

\author{
Asesor: \\ Dr. David Lozada Martínez \\ (0000-0001-5672-1462) \\ Lima - Perú




\section{Resumen}

La investigación tuvo como propósito determinar la relación que existe entre las dimensiones del bienestar psicológico y el engagement en colaboradores de una universidad privada de Lima Metropolitana. Para lo cual, se utilizó la Escala de Bienestar Psicológico de Ryff adaptada en Perú por Pérez, M. (2017) y la escala UWES (Utrecht Work Engagement Scale), adaptada al Perú por Hernández, R (2017). La muestra estuvo conformada por 92 trabajadores elegidos bajo un muestreo no probabilístico por conveniencia, con un rango de edad que fluctúa de 20 a 50 años. Los resultados de la investigación demuestran que existe relación estadísticamente significativa entre las variables de este estudio. Asimismo, el bienestar psicológico es mejor explicado bajo la dimensión vigor del engagement, pues la relación es estadísticamente significativa moderada, en las dimensiones relaciones positivas y dominio del entorno.

Palabras clave: bienestar psicológico, engagement, vigor, relaciones positivas, dominio del entorno. 


\begin{abstract}
The research aimed to determine the relationship between dimensions psychological well-being and engagement in workers of a private university in Metropolitan Lima. For this, we used Ryff's psychological well-being Scale adapted in Perú by Pérez (2017) and the UWES scale (Utrecht Work Engagement Scale), adapted to Peru by Hernández (2017). The sample consisted of 92 workers chosen under a non-probabilistic convenience sampling, with an age range that ranges from 20 to 50 years. The results of the investigation show that there is a statistically significant relationship between the variables of this study. Likewise, Psychological Wellbeing is better explained under the vigor dimension of engagement because the relationship is statistically significant moderate.
\end{abstract}

Keywords: psychological well-being, engagement, vigor, positive relations, environmental mastery. 
Tabla de contenido

INTRODUCCIÓN

MÉTODO

Tipo y Diseño de Investigación

Participantes

Instrumentos de Medición

39

Procedimiento

40

Análisis de Datos

40

RESULTADOS

42

DISCUSIÓN

48

REFERENCIAS BIBLIOGRÁFICAS

56

ANEXOS

61 
Tabla 2: Descripción demográfica de la muestra

Tabla 3: Análisis de fiabilidad de las escalas usadas

Tabla 4: Análisis de fiabilidad de los puntajes de los instrumentos usados.

Tabla 5: Análisis descriptivos de los puntajes de los instrumentos usados.

Tabla 6: Correlación de Pearson entre las dimensiones de la Escala de Bienestar Psicológico de Ryff y las dimensiones de The Utrecht Work Engagement Scale 46

Tabla 7: Correlación de Pearson entre la Escala de Bienestar Psicológico de Ryff y The Utrecht Work Engagement Scale - UWES.

Tabla 8: Correlación de Pearson entre la Escala de Bienestar Psicológico de Ryff y las dimensiones de The Utrecht Work Engagement Scale - UWES 
Índice de figuras

Figura 1: Modelo de Demandas y Recursos Laborales

Figura 2: Modelo Demandas Laborales

¡Error! Marcador no definido.5 


\section{Introducción}

Durante años la organización ha sido considerada la principal fuente de estabilidad económica, crecimiento profesional y satisfacción de la sociedad, la cual, está compuesta principalmente por personas que se involucran y que interactúan entre sí, bajo una estructura diseñada para lograr un determinado objetivo (Thompson, 2007).

Sabiendo ello, es importante reconocer que uno de los ámbitos organizacionales más relevantes dentro de la sociedad, es el ámbito educativo y que además no ha sido investigado en su totalidad como una organización u empresa.

Sobre la base de la experiencia dentro del sector educativo, se puede afirmar que este es un espacio donde las personas se desarrollan e interactúan de manera diaria y constante para cumplir, en primera instancia, las funciones encomendadas de cada puesto de trabajo, intentando como organización cumplir las expectativas del cliente, en este caso el estudiante (Indacochea, Pincay, Reyes, García \& Indacochea, 2018)

La problemática de esta investigación nace del cuestionamiento acerca del colaborador que no está cómodo en su trabajo, no disfruta lo que hace, ni tampoco se vincula o compromete con los objetivos de la organización.

Podrían ser muchas las variables que intervienen en el proceso que lleva al colaborador a un estado de bienestar mediante una vinculación con la empresa, como clima laboral, cultura organizacional, salarios entre otros (Indacochea et al., 2018).

Sin embargo, son el bienestar psicológico y engagement los constructos que, dentro de un contexto educativo, podrían describir el por qué los colaboradores se comprometen de tal forma, que alineen sus metas a los de la organización (Indacochea et 
al., 2018), teniendo repercusión en la atención a estudiantes y cumplimiento de funciones relacionadas al servicio de alumnos.

Tanto el bienestar psicológico como el engagement provienen de la psicología positiva; un campo de investigación que nace en el año 1998 con Martin Seligman (Zamora, 2016). Es importante tener en cuenta que antes de la Segunda Guerra Mundial la psicología tenía tres propósitos según Lupano y Castro (2010). El primero es sanar las consideradas enfermedades mentales que hasta esa fecha aún se estaban dando a conocer, motivar que las personas tengan una vida más productiva y, finalmente, promover las potencialidades del ser humano.

Sin embargo, la historia cambia de rumbo y desde la Segunda Guerra Mundial, los psicólogos se enfocaron en curar y remediar enfermedades mentales y problemas humanos fruto de lo vivido en esa época (Park, Peterson \& Sun, 2013). Años después se inicia el movimiento de la psicología positiva Lupano y Castro (2010) refieren que "La Psicología no es solo el estudio de la debilidad y el daño, es también el estudio de la fortaleza y la virtud. El tratamiento no es solo arreglar lo que está roto, es también alimentar lo mejor de nosotros" (p.2).

Al inicio, Martin Seligman, el autor de la psicología positiva refiere que la felicidad es la base de su enfoque, planteando la teoría de La Felicidad Auténtica la cual divide a la felicidad en tres componentes: emoción positiva, compromiso y sentido (Seligman, 2016).

Años más tarde se da cuenta de que la base real es el bienestar y que este constructo se mide en base al florecimiento o crecimiento de la persona. De esta manera nace la teoría del bienestar, que se divide en cinco elementos: emociones positivas, entrega/compromiso/ involucramiento, relaciones, significado y logros (Seligman, 2016). 
En el proceso de conceptualizar el bienestar, anteriormente denominado felicidad, se observó el interés en aspectos que se relacionen a las fortalezas del ser humano (Levitas, 2007), siendo la base en la psicología positiva, para poder fundamentar el bienestar psicológico y engagement, pues dentro de las dimensiones iniciales se plantea que, para hallar la auténtica felicidad y el bienestar, el constructo base es el compromiso o involucramiento (Seligman, 2016) términos que hoy son agrupados en el Engagement.

Así también, existe relación entre las variables del bienestar de Ryff y Singer (2006) y lo que propone Seligman (2016) pues en ambos se describe que el ser humano posee dimensiones orientadas al crecimiento, a las relaciones interpersonales y el propósito de vida (Perán, 2014).

Seligman es considerado el propulsor de la psicología positiva, la cual busca entender los aspectos que previenen enfermedades y luchan por mantener un buen estado de salud mental (Vera, 2006).

Con este enfoque como cimiento principal, han aparecido diversos campos de acción, como por ejemplo en la psicología organizacional, donde el bienestar psicológico y engagement surgen como temas que se oponen a lo ya investigado ampliamente en la rama que trata a las personas dentro de ámbitos laborales (Salgado \& Peiro, 2008).

Temas como trastornos psicosociales, enfermedad, burnout y problemas que afectan al ser humano, han sido por mucho tiempo parte fundamental del estudio dentro de la sociedad; sin embargo, en las últimas décadas las variables de esta investigación han tomado importancia, siguiendo la misma línea ya descrita como psicología positiva, poniendo al centro del estudio las fortalezas del ser y no las debilidades (Park et al., 2013).

A lo largo del desarrollo de esta investigación, como ya se mencionó, se ha encontrado que diversos autores como García y Gonzales (2000), se han encargado de 
estudiar en qué se basa vivir bien y sentirse bien y en realidad esta premisa tiene intereses ancestrales y ha surgido nuevamente por la necesidad de explicar cómo es posible que algunos individuos puedan superar obstáculos y ser felices logrando un buen desempeño en el ámbito laboral.

El constructo bienestar se forma del sustantivo bien y del verbo estar, definiéndose como una sensación de plenitud, satisfacción, armonía y paz (Oblitas, 2008) que se diferencia de la felicidad, pues bienestar es un estado prolongado en base a la aceptación y valoración de la propia condición de vida (Cassaretto \& Martínez, 2017).

La segunda variable de esta investigación, engagement, no posee una traducción exacta y comúnmente suele confundirse con compromiso o fidelidad, siendo esta una herramienta para medir el nivel de vinculación del colaborador con la organización. Comúnmente puede decirse que el engagement es un constructo teórico opuesto al burnout (Salanova \& Schaufeli, 2004).

En la actualidad, existen múltiples investigaciones que se basan en comprender la relación que tiene el bienestar psicológico, el individuo y su influencia, sea positiva o negativa, en las actividades diarias que realizan; pero fundamentalmente se enfocan en como esta variable puede ser un predictor del estado de salud del ser humano (Amasifuén, 2016).

Dentro de los estudios revisados para la realización de la presente investigación se puede decir, que existe un amplio interés en evaluar cómo la variable bienestar psicológico puede tener repercusiones en el deporte, rendimiento académico Barrantes y Ureña (2015), relación de pareja, el trabajo, personalidad, desempeño y calidad de vida del ser humano (Loera, Balcázar, Trejo, Gurrola, \& Bonilla 2017); lo cual evidencia que existe interés en conocer, cómo es que el bienestar está presente en cada ámbito de la vida 
de las personas.

De esta manera el bienestar psicológico se vincula a la satisfacción de las necesidades básicas y se sustenta en la teoría de la motivación humana, planteada por Maslow en el año 1943. Montalvo y Plasencia (2015) refieren que cada aspecto del ser humano está dirigido a la autorrealización, la cual entre sus múltiples factores destacan el sentimiento de afecto, de pertenencia y la alta autoestima.

Por lo explicado, el constructo bienestar psicológico va más allá del estado de ánimo y la felicidad, hoy en día las investigaciones lo abordan como un elemento aparte, de ahí que son múltiples las variables con las cuales se ha querido correlacionar este constructo, entre ellas las que guardan mayor relación son: la motivación, las emociones, la personalidad sin importar si este enfoque es hedónico o eudamonico (Meneses, Sánchez, \& Sepúlveda, 2016).

En base a lo investigado acerca del bienestar psicológico, las muestras que han sido sujeto de evaluación en su mayoría son: áreas académicas o muestras de servicio a la ciudadanía tales como enfermos, oficiales, policías, operarios o personas de baja instrucción académica (Chávez, 2008).

Cabe resaltar también, que las variables con las que se ha relacionado en mayor medida el bienestar psicológico son: estrés, apoyo organizacional percibido, burnout, perfiles motivacionales, involucramiento entendido como engagement, clima laboral y satisfacción laboral, encontrando que estas tres últimas mencionadas se relacionan positivamente al bienestar psicológico, es decir afectan el bienestar de la población evaluada (Chávez, 2008).

Asimismo, algunas investigaciones en relación al sexo, las mujeres obtienen puntajes significativamente más altos que los varones, por ejemplo, Ryff y Keyes (1995); 
del mismo modo, Cubas (2003) en una muestra de universitarios ratificó que de forma general las mujeres puntuaron más alto que varones en todas las sub escalas, con excepción a la sub escala de autonomía.

En cuanto a la edad, Alandete (2013) plantea que con el avance del tiempo las sub escalas autonomía y manejo del ambiente aumentan de forma significativa a diferencia de las dimensiones sentido de vida y crecimiento personal, pues estás disminuyen con el pasar de los años, mientras que la autoaceptación, no muestra variación significativa.

Por otro lado, Chávez (2008) ha intentado investigar si el bienestar psicológico está relacionado con el nivel socioeconómico o educativo del ser humano, encontrando que si bien es cierto la pobreza representa un claro peligro, la obtención de dinero no significa que el bienestar de la persona se beneficie.

Asimismo, en países desarrollados y subdesarrollados plantean que mientras los seres humanos se esfuercen más en alcanzar metas materialistas, más bajo será su bienestar, pues según algunas investigaciones el deseo de lograr metas intrínsecas incrementa el bienestar, por el contrario, si nuestro progreso se basa en el logro de metas extrínsecas como el aspecto económico, el bienestar no demuestra ningún incremento (Cassaretto \& Martínez, 2017).

Siguiendo esta misma línea, se encontró que las subescalas que más se relacionan al estatus socio económico son autoaceptación, manejo del ambiente y crecimiento personal. En el lado educativo, las dimensiones que describen de forma significativa el bienestar psicológico son: crecimiento personal y sentido de vida (Ryff \& Singer, 2006).

El termino bienestar es un concepto que no resulta únicamente de las necesidades materiales, es decir bienestar no solo hace referencia a un estado físico, sino también al estado mental y emocional del ser humano (Garrido, 2006). 
Lo último mencionado, indica que existen otras razones que provocan que los colaboradores se comprometan de manera excepcional a sus trabajos, además es importante entender que estas razones, son más valoradas que las razones convencionales tales como dinero, premios o bonos, siendo este un punto de investigación que se abordará en este estudio, ya que, si se logra entender qué involucra el bienestar psicológico se podrá plantear herramientas de mejora o sostenibilidad a esta variable dentro de la organización, lo cual será un punto de inicio a otras investigaciones.

A partir de ello, se han intentado formular diversos conceptos acerca del bienestar psicológico, cuya terminología es compleja. Leturia (2001) plantea las siguientes dimensiones: congruencia, felicidad, afecto negativo y afecto positivo, así mismo, refiere que estas se dan en base a las percepciones individuales sobre la propia calidad de vida.

Por otro lado, se ve al bienestar psicológico como un recurso que previene y protege al ser humano de patologías y que además de ello, se vincula de manera intrínseca a la salud mental (Zúñiga, 2010).

Así también, Barrantes y Ureña (2015) refieren que "El bienestar psicológico trasciende los estados afectivos y las valoraciones a partir de la satisfacción vital y propone que el bienestar se encuentra en aspectos que buscan y facilitan la realización de las personas y su desarrollo óptimo" (p.4).

Desde un lado más amplio, tenemos a Carol Ryff, quien conceptualiza el bienestar psicológico como el deseo de perfección y el alcance del propio potencial, todo ello relacionado al propósito de vida y el significado de ella para el ser humano, así como la superación de desafíos y el logro de objetivos de vida valiosos; esto hace énfasis en un 
correcto funcionamiento de la persona más que en sus sentimientos (Ryff, 1989).

Monzón (2016), planteo que es importante describir dentro del concepto de bienestar, los rasgos característicos que son valorados de forma positiva, incluyendo actividades conductuales como dormir, comer, trabajar bien, mantener relaciones interpersonales efectivas y dominar las tareas apropiadas, así como incluir el sentimiento de pertenencia y aceptación con la propia existencia.

Corral (2012) plantea que todas aquellas personas que poseen bienestar psicológico son empáticas, amorosas y generan vínculos afectivos positivos con los otros, así mismo se preocupan por los demás y son altruistas.

Sin embargo, para fines de esta investigación se consideraron los siguientes conceptos:

Pérez, D. (2017) “El bienestar psicológico está vinculado con tener un propósito en la vida, en que la vida adquiera significado para uno mismo, con los desafíos y con un cierto esfuerzo por superarlos y conseguir metas valiosas" (p.6).

Así mismo Chávez (2008) plantea "el bienestar psicológico mide no sólo si el sujeto se siente feliz, sino cómo se encuentran las diferentes dimensiones de su funcionamiento positivo que tendrán una relación teóricamente fundamentada con su autorrealización y crecimiento personal” (p.10).

El bienestar psicológico en el trabajo se basa en tres elementos: la coherencia entre los objetivos y con las estrategias para conseguirlos, y el hecho que su consecución suponga un reto y conlleve poner en funcionamiento capacidades aun no desarrolladas plenamente por la persona (p.20).

Por otro lado, Zúñiga (2010), refiere que son diversos los enfoques y teorías que tratan de explicar el bienestar psicológico. Existen dentro de la literatura dos perspectivas 
bienestar hedónico, el cual hace referencia a considerar al bienestar como la presencia de emociones positivas y la ausencia de emociones negativas más asociado a la literatura que explica sobre bienestar subjetivo el cual contempla principalmente el componente afectivo. Tenemos también a los enfoques eudamonicos que se refieren a la forma plena de vivir y a otorgarle características que son potencialmente valiosas a los seres humanos, en donde Martín Seligman toma gran protagonismo.

La primera teoría es la planteada por Seligman, quien enfoca su vida al estudio de la psicología positiva, dando su mayor aporte en una teoría que en un inicio investiga la felicidad; sin embargo, se reestructuró creando un enfoque de elecciones denominada Teoría del Bienestar (Seligman, 2002). Esta se focaliza en lo que el ser humano busca, planteando elementos que poseen tres propiedades para considerarse como tal: contribuyen al bienestar, son independientes uno del otro y se busca por sí mismo y no para llegar a otro elemento (Meneses et al., 2016).

Es así que esta teoría tiene cinco elementos agrupados en el modelo PERMA que incluyen: emociones positivas, como experimentar gratitud, amor y felicidad; engagement o involucramiento que se refiere a experimentar emociones que motivan la concentración y nos proponen grandes retos; relaciones positivas como la forma en que nos relacionamos con otras personas dentro de un contexto determinado, es el elemento más cercano a la felicidad y se relaciona a bondad, compasión, altruismo y empatía; sentido/significado elemento subjetivo pues se relaciona al significado y sentido que se le da al logro de objetivos planteados; logros o compromiso como el propósito que da sentido a la vida del ser humano (Meneses et al., 2016).

Se considera que esta teoría se enfoca en darle un significado y sentido a las cosas que hacemos, es encontrar un propósito de vida y en base a ello sentir bienestar, esto se 
logra no solo con emociones positivas, sino también con vivencias positivas que se forman por relaciones positivas, es por ello que esta teoría podría ser clave en la investigación en temas acerca del bienestar.

Existen también teorías que plantean que el bienestar es innato y se da por la búsqueda de ciertos elementos que el ser humano ya posee y solo necesita encontrarlos, tal es así que Ryan y Deci (2000), plantean la "teoría de la autodeterminación” o "Self Determination Theory" quienes parten de la idea de que las personas poseen necesidades psicológicas innatas como ser competentes, autónomos y estar en constante relación interpersonal, donde el contexto social toma importancia pues podría facilitar u obstaculizar el correcto funcionamiento. Entonces las tres variables mencionadas serian propulsoras del bienestar subjetivo y además de un óptimo desarrollo social (Zúñiga, 2010).

El modelo de acercamiento a la meta descrita por Brunstein (1993), plantea que la base fundamental del bienestar está en las metas y los valores como guías de la vida; es decir las personas poseen bienestar en función del logro de metas planteadas. En donde obtendrán mayor bienestar siempre y cuando las metas sean congruentes con los recursos personales que posean (Cuadra \& Florenzano, 2003).

Se considera que esta teoría carece de elementos para poder describir al bienestar pues, asumiendo que el ser humano puede sentirse bien por el simple hecho de lograr una meta, la pregunta clave seria ¿dónde quedaría el aspecto interpersonal y gregarismo? que es fundamental para el ser humano, además forma parte de las necesidades básicas de Maslow que hasta hoy tienen relevancia (Montalvo \& Plasencia, 2015).

Otra de las teorías importantes es la planteada por Ryff y Keyes (1995), cuyo enfoque es eudaimónico y además recopiló información de varias teorías, alineándolas en 
6 dimensiones: la auto - aceptación, las relaciones positivas con los demás, la autonomía, el dominio del entorno, el propósito en la vida y el crecimiento personal.

Este modelo multidimensional propone que el bienestar psicológico es una variable compleja y que supera la sencilla estabilidad de los afectos positivos sobre los negativos y lo relaciona además con la valoración de las metas alcanzadas y la forma de vida o calidad de vida (Casullo, 2002). Con el pasar de los años esta teoría no ha tenido grandes modificaciones, y sus dimensiones se han mantenido estables (ver tabla 1).

La primera dimensión es la Autoaceptación, hace referencia a la satisfacción con uno mismo, reconociendo nuestras limitaciones lo cual eleva la autoestima pues se reconoce los recursos personales así mismo, podemos deducir que este aspecto logra que las personas logren emociones positivas como resultado de identificar sus fortalezas, según lo planteado en el enfoque de la psicología positiva (Rodríguez y Berrios, 2012).

Por otro lado, el crecimiento personal, se enfoca en que el ser humano y su vida están sometidos a un proceso de cambio y aprendizaje constante. El término también conocido dentro de la psicología positiva como florecer (Seligman, 2016), explica que la persona debe desarrollar su potencial con el objetivo de crecer y lograr el desarrollo de sus capacidades.

Así mismo, la dimensión propósito de vida, está enfocado en la dirección que tiene la persona de a dónde quiere llegar, para qué o por qué lo hace, relacionándose con los valores, políticas, filosofías y significado, haciendo referencia a lo que la persona desea lograr y el porqué de ello (Seligman, 2002).

Con respecto, a la dimensión control del entorno, la persona debe desarrollar capacidades que le permitan satisfacer sus necesidades, todo ello dentro de ambientes que el mismo selecciona e identifica como favorecedores (Rodríguez y Berrios, 2012). 
Por otro lado, la dimensión relaciones interpersonales, explica que las personas son capaces de crear relaciones afectivas positivas, inspirando confianza, calidad, empatía e intimidad con otros (Medina, Gutierrez \& Padros, 2013).

Finalmente, la dimensión autonomía, hace referencia a dos aspectos de la persona, a la confianza en las opiniones propias, sin temer a que sean opuestas a la de los demás y a la capacidad de regulación y resistencia a la presión social (Meneses et al., 2016).

Esta teoría desarrolla con claridad el bienestar psicológico pues plantea, aspectos que enfoques anteriores han desarrollado, agrupándolas en una sola; así mismo, continúa con lo planteado por la psicología positiva, la cual, se enfoca en las potencialidades del ser humano.

Por otro lado, esta teoría explica también la importancia que tienen el planteamiento y logro de metas, así mismo refuerzan las relaciones interpersonales positivas, mencionando también aspectos intrapersonales del ser humano como autonomía, autoaceptación, crecimiento y propósito de vida como elementos que pueden ayudar al dominio del entorno (Vera, Urzua, Silva, Pávez \& Celis, 2012).

Asi mismo, esta teoria muestra interrelación entre las variables explicando, por ejemplo, que la aceptación que se tiene de uno mismo está vinculada a dimensiones como autonomía y crecimiento personal, el propósito de vida puede estar relacionado al crecimiento; por lo tanto, el estudio del bienestar a través de este enfoque podría ayudar a encontrar técnicas de mejora y crecimiento para la persona (Rodríguez, Quiñones 2012). 
Tabla 1

Dimensiones del Bienestar.

\begin{tabular}{lll}
\hline \multicolumn{1}{c}{ Dimensiones } & \multicolumn{1}{c}{ Puntuación alta } & \multicolumn{1}{c}{ Puntuación baja } \\
\hline Auto - & Actitud positiva: de sí mismo, de sus & Insatisfecho consigo mismo, desea ser \\
aceptación & actitudes y del pasado. & $\begin{array}{l}\text { distinto y tiene actitud negativa hacia el } \\
\text { pasado. }\end{array}$ \\
Relaciones & Genera relaciones de confianza con & Tienen dificultades para generar \\
positivas & otros. & relaciones interpersonales. \\
Autonomía & Autodeterminado- independiente & Preocupación por las opiniones externas \\
& & y las exceptivas generadas hacia él. \\
Dominio del & Posee confianza en el manejo del & Tiene dificultad para manejar eventos \\
Entorno & entorno. & cotidianos. \\
Propósito en la & Posee metas y le ha dado sentido a la & No le ha dado significado a la vida y no \\
vida & vida. & posee metas. \\
Crecimiento & Sentimiento de desarrollo continuo. & Sentimiento de estancamiento personal. \\
personal & &
\end{tabular}

Nota: Recuperado de Revisión de las principales teorías de bienestar psicológico. (Ryff, 1989)

En cuanto al engagement podemos decir que uno de los primeros autores en investigar acerca de esta variable fue William Kahn en 1990, el cual lo define como una energía acumulada con el fin de alcanzar metas organizacionales (Kahn,1990).

El término engagement proviene de la literatura internacional y se utiliza de forma anglosajona para hacer referencia a entusiasmo por el trabajo (Juárez, Hernández, Flores \& Camacho, 2015).

Sin embargo, es de importancia mencionar que durante los últimos años el concepto de engagement ha resultado de dos enfoques: como un concepto en sí mismo confundiéndolo con las variables compromiso e involucramiento y en oposición a burnout 
(Cárdenas, 2014).

Para esto, es fundamental mencionar que la traducción al español es complicada, y los autores principales refieren que no se ha encontrado un término en español que abarque todo lo referido a este constructo, es por eso la dificultad en su conceptualización.

Así mismo, se puede afirmar que este término es comúnmente utilizado como una variable que supera el compromiso y hace referencia a involucramiento con el trabajo, siendo ambos insuficientes para explicarla, pues esta variable explica la implicación de un colaborador con la organización para la que trabaja (Cárdenas, 2014).Los resultados de lograr que un empleado tenga un alto nivel de engagement consiguen trabajadores más comprometidos, demostrando un incremento de la productividad y de la calidad, además de la disminución de errores en los procesos y mejorando el servicio teniendo clientes más satisfechos, lo cual se replica en todos los sectores laborales (Giraldo \& Pico, 2012).

Siguiendo con esta explicación, decimos que parte de la historia del nacimiento de esta variable se relaciona a la búsqueda que varios investigadores tuvieron por conocer más acerca de qué factores son positivos para el ser humano dentro de las organizaciones, es ahí en donde el engagement aparece como solución a otro concepto denominado “Burnout”, mencionado líneas arriba, que es desarrollado por Freudenberger (1974) pero que toma mayor relevancia a partir del año 1980 (Carlin \& de los Fayos, 2010) y es conceptualizada bajo tres factores: cansancio emocional, despersonalización y baja realización personal (Gutiérrez, Loboa \& Martínez, 2017), en oposición a estos factores se define la composición del empleado engagement quien percibe su trabajo como un reto a superar y se ve a sí mismo capaz de superar y resolver sus propias necesidades (Liñán, 2016).

Por otro lado, las variables que han sido estudiadas junto al engagement son: 
cultura organizacional, felicidad, motivación laboral, trabajo emocional, satisfacción laboral, estilos de liderazgo, salud laboral, estrés, comunicación laboral y compromiso organizacional, haciendo hincapié en que el último mencionado no tiene la misma significancia que el constructo de este estudio. Así mismo, estas investigaciones en su mayoría han sido aplicadas en muestras académicas, colaboradores del estado y personal de servicio (Cárdenas, 2014).

Al nacer, el engagement en oposición al burnout, se puede definir y así mismo confundir en muchos casos como compromiso, entusiasmo, entre otros; sin embargo, como ya hemos mencionado antes, el engagement supera dichas variables, por lo que no se ha encontrado traducción al español, pues engagement no es: work involvement que significa implicación en el trabajo; organizational commitment que significa compromiso organizacional; o work dedication que se refiere al dedicación al trabajo (Hernández, 2017).

A pesar de la dificultad de conceptualizar esta variable por las razones ya mencionadas, existen autores que en los últimos 20 años han intentado hacerlo, tal es el caso de los siguientes mencionados.

Kahn (1990) define al engagement como aprovechamiento de los roles de trabajo por los mismos colaboradores, esto se da en base a la exposición de los diversos recursos laborales al colaborador, así mismo esta definición se enfoca en como el colaborador se desenvuelve y la forma en la que realiza sus funciones.

Maslach y Leiter (1997) siguen una línea diferente, ellos asumen que el engagement está en oposición del burnout y sus componentes fundamentales son: energía, compromiso y eficiencia, mencionando que el resultado engagement / burnout se basa en el nivel de exigencias y el logro de estas dentro del trabajo. 
Schaufeli, Salanova, Gonzáles-Roma y Bakker, (2002) plantean que el engagement es un estado mental positivo cuya base se da por vigor, dedicación y absorción. Además, este concepto engloba el aspecto físico, cognitivo y afectivo del ser humano logrando que el engagement sea resultado de una vivencia positiva dentro del trabajo.

Los dos últimos conceptos más relevantes de esta última década la plantean: Gebauer, Lowman y Gordon (2008) en donde el engagement es el deseo personal de los colaboradores de hacer y dar más por su trabajo y funciones, siendo parte fundamental la conexión entre la empresa y el trabajador, pues asumen como propio el crecimiento de la empresa.

Esta conceptualización es fundamental para entender por qué un colaborador es engaged, pues esta definición también involucra a la pasión, el entendimiento y responsabilidad que asume dentro de la organización. Por otro lado, Leiter y Bakker (2010) se refieren al engagement como el resultado de satisfacción laboral y compromiso organizacional.

Cada concepto alimenta lo que significa el termino engagement; sin embargo, para efectos de esta investigación consideraremos la conceptualización realizada por (Schaufeli et al., 2002).

El engagement es un estado positivo, satisfactorio y relacionado al trabajo, caracterizado por vigor, dedicación y absorción. Más que un estado específico y momentáneo, el engagement se refiere a un estado afectivo-cognitivo más persistente e influyente, que no está enfocado sobre un objeto, evento, individuo o conducta en particular (pp.11-12).

Por otro lado, las teorías acerca del engagement, a la fecha aún se encuentran en 
desarrollo teórico, y con el pasar de los años se han ido descartando algunas que no aportan al crecimiento de esta variable. Es por ello, que los modelos que mejor explican al engagement son: Modelo DRL de Bakker y Demerouti y Modelo JD- R de Bakker y Leiter.

El modelo de Demandas y Recursos Laborales de Bakker y Demerouti se centra en lo motivacional, tomando en cuenta las dos realidades del campo laboral, el engagement como bienestar y el burnout. Tratan a ambas pues se piensa que están relacionadas entre sí, explicando dos procesos. Ante las demandas laborales aquellas personas que no pueden afrontar dicha exigencia presentan Burnout y aquellas que logran afrontar de forma positiva inician un proceso motivacional que los lleva al engagement (ver figura 1), ambos procesos tienen consecuencias negativas y positivas respectivamente (Bakker \& Demerouti, 2013).

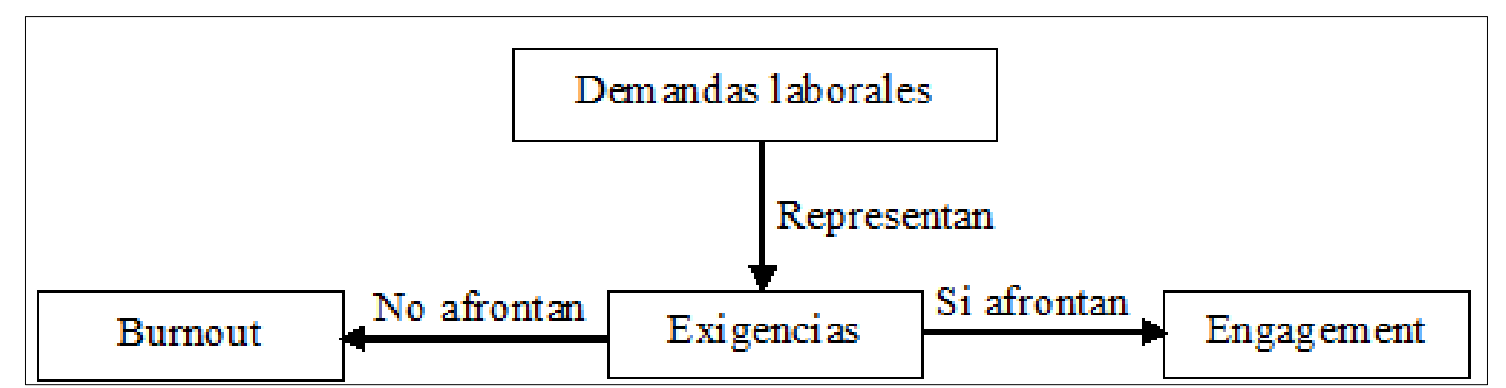

Figura 1. Modelo de Demandas y Recursos Laborales. Fuente: Liñán (2016)

El modelo de JD-R plantea que el engagement dentro del trabajo se puede pronosticar a partir de los recursos laborales y los recursos personales, en donde los recursos laborales son los estímulos que promueven el esfuerzo de los colaboradores, (estimular aprendizaje, crecimiento o desarrollo) además son aquellos que permiten tener un alto engagement cuando hay exigencias que afrontar, amortiguando los efectos negativos (Leiter \& Bakker, 2010).

Y los recursos personales sirven para pronosticar colaboradores engaged, 
tomando relevancia la autoevaluación positiva relacionada a la resiliencia, la capacidad para controlar e impactar el ambiente, motivación, desempeño en el trabajo, satisfacción vital, autoeficacia, optimismo, esperanza y resiliencia (Leiter \& Bakker, 2010).

Es así como, una mezcla de recursos laborales y recursos personales de los trabajadores permiten obedecer favorablemente a las demandas laborales promoviendo al engagement en sus tres factores: vigor, dedicación y absorción (Schaufeli et al., 2002).

La primera dimensión es vigor; está relacionado a altos niveles de energía y resistencia mental, durante el periodo o jornada laboral, implica el hecho de que el colaborador tiene el deseo intrínseco de dar más energía sin sentirse cansado, a pesar de que existan diversas dificultades (Schaufeli \& Bakker, 2003).

Así mismo, tenemos a la dimensión dedicación, relacionada al significado que tiene el trabajo para el colaborador, es decir el entusiasmo o vinculación con sus funciones que tan orgulloso esta de ellas, relacionándolo con el reto que frecuentemente representa su jornada laboral (Salanova \& Schaufeli, 2004).

Finalmente, la dimensión absorción, hace referencia a la satisfacción que tiene el colaborador durante su periodo de trabajo, es decir el placer causado por no darse cuenta del paso del tiempo, mientras se está realizando las funciones del puesto laboral (Schaufeli \& Bakker, 2003).

Para efectos de la presente investigación se utilizará el último modelo descrito pues, describe al engagement como concepto en sí mismo y no bajo la premisa de que se opone a otra variable (ver figura 2). Así mismo, se relaciona con la investigación y las subdimensiones de la prueba que se utilizara para la variable bienestar psicológico, pues Salanova y Schaufeli (2004) plantean que una de las causas del engagement está en el capital humano y sus recursos personales como autonomía, relaciones con el entorno y 
relaciones positivas.

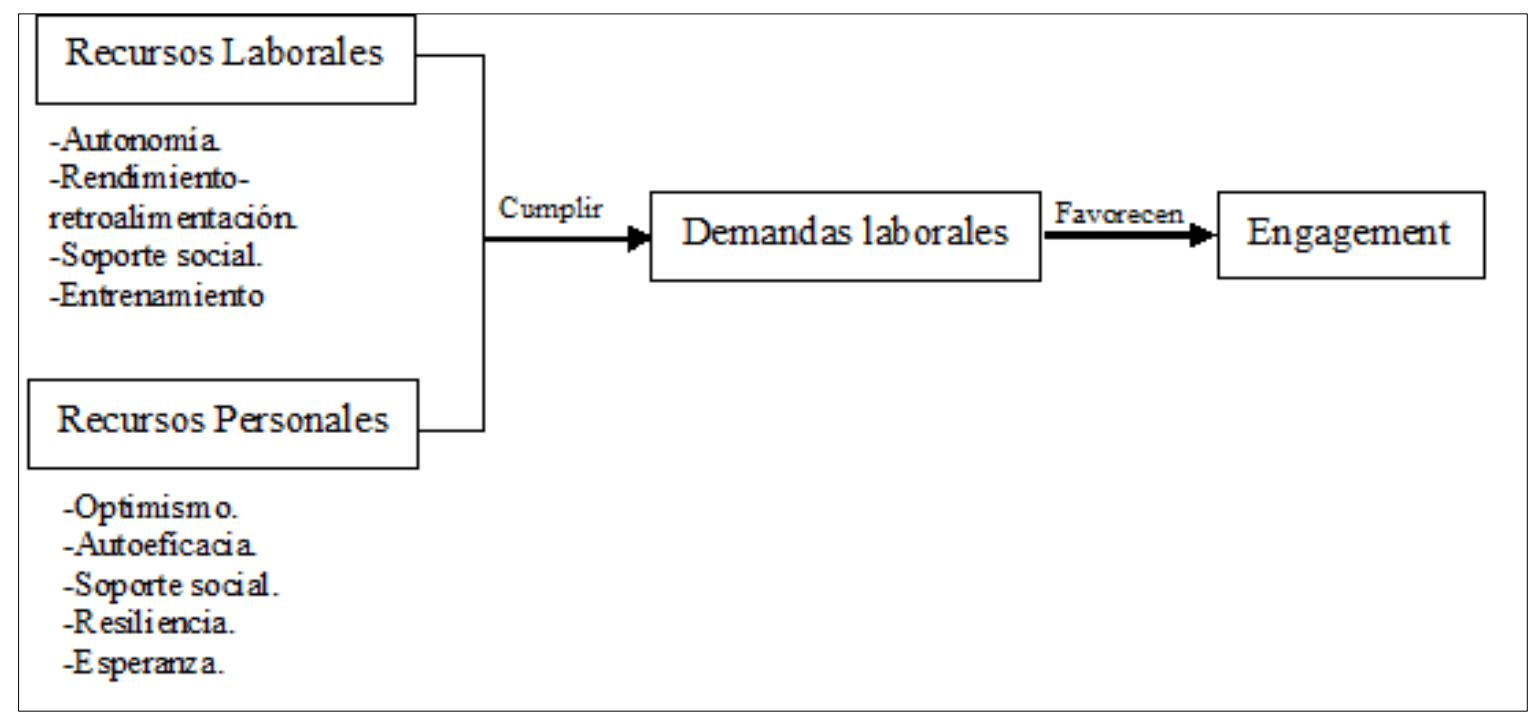

Figura 2. Modelo Demandas Laborales - Recursos. Fuente: Espinoza (2017)

Durante mucho tiempo los temas relacionados a la psicología positiva, no han tenido espacio de estudio en el campo laboral; sin embargo, en los últimos años han tomado gran relevancia, es así que se ha insertado diversos términos en el mundo de la gestión de recursos humanos y las investigaciones surgieron como una necesidad de ver las implicancias del ámbito laboral en nuestro contexto social, por ello se describen algunos antecedentes importantes que estudian las variables de esta investigación de manera conjunta, ejemplo de ello son:

Jena, Pradhan y Panigrahy (2018) realizaron una investigación cuyo objetivo se enfocó en dos aspectos: identificar el efecto directo del engagement del colaborador en la confianza de la organización y, en segundo lugar, investigar el efecto indirecto del bienestar psicológico y el liderazgo transformacional en la relación entre el engagement de los trabajadores y la confianza de la organización. La muestra estuvo conformada por 511 ejecutivos de recursos humanos cuyas edades fluctúan entre 29 y 38 años a quienes se les aplicaron las siguientes escalas: para evaluar engagement se utilizó la Escala de Utrecht Work Engagement (UWES), para bienestar psicológico se aplicó la Escala de 
Bienestar Psicológico de Ryff, para medir liderazgo transformacional se utilizó el Inventario de comportamiento de liderazgo transformacional y finalmente, para medir la confianza organizacional se aplicó la Escala de Índice de Confianza Organizacional. Los resultados hallados demuestran que el engagement tiene relación estadísticamente significativa con la confianza organizacional, además el bienestar psicológico y el liderazgo transformacional poseen influencia estadísticamente significativa en la relación entre el engagement y la confianza organizacional así mismo, el liderazgo de transformacional tiene influencia estadísticamente significativa en la relación entre el compromiso de los empleados y la confianza de la organización., es decir que mientras la organización tenga líderes que compartan los objetivos y que demuestren ética y confianza con los colaboradores, se generara un ambiente de trabajo más atractivo generando colaboradores engaged y por consecuencia bienestar psicológico.

Zulueta (2019) realizo una investigación acerca del impacto del bienestar y el engagement en profesionales de enfermería que brindan cuidados a pacientes paliativos. Este estudio, tuvo como objetivos, en primer lugar, explicar la relación del engagement y bienestar psicológico con la calidad del cuidado a pacientes paliativos, así mismo, investigar la relación de estas variables con ansiedad hacia la muerte del paciente paliativo. La muestra estuvo conformada por 176 profesionales de enfermería del área de pacientes paliativos cuyas edades fluctúan entre 20 y 50 años entre enfermos y auxiliares de enfermería. Los instrumentos utilizados fueron: Cuestionario de Calidad del Cuidado Enfermero Paliativo (CCEP), Escala de Miedo ante la muerte de Collet-Lester (CLFDS) versión española, Escala de Bienestar Psicológico de Ryff (BP) y Escala Utrech Work Engagement Scale (UWES). Los resultados demuestran que los profesionales de enfermería con mayor bienestar psicológico y engagement brindan mejor calidad de cuidados a pacientes paliativos; siendo crecimiento personal y dedicación las sub escalas 
que explican mejor la variable bienestar psicológico y engagement respectivamente. Por otro lado, se halló que la ansiedad ante la muerte de otros, influye negativamente en el bienestar psicológico, pero no en el engagement; esto último, puede deberse a que los enfermeros de estas áreas perciben la muerte como algo natural de la profesión.

Amasifuén (2016) investigó acerca del bienestar psicológico e involucramiento laboral (engagement) en colaboradores de un organismo descentralizado de la municipalidad provincial de Trujillo - 2016. Tuvo como objetivo analizar la relación de las variables mencionadas; esto lo realizo en una muestra conformada por 301, de ambos géneros cuyas edades oscilaban entre 20 a 63 años, contratados y nombrados, los cuales fueron seleccionados de manera aleatoria. Para esta investigación se utilizó la Escala de Bienestar Psicológico de José Sánchez - Cánovas y el Cuestionario de Engagement (Implicación emocional) y cuenta con las dimensiones vigor, dedicación y absorción. A través de la aplicación de la escala y cuestionario se comprobó que existe relación estadísticamente significativa entre bienestar material y bienestar laboral y no hay relación entre relaciones con la Pareja y las dimensiones de involucramiento laboral (vigor, absorción, dedicación).

Grueso, Rey, Gonzales, Ardila y Pineda (2013) investigaron las acciones de promoción de la salud organizacional y su relación con variables estructurales y el bienestar de los trabajadores, todo ello bajo el modelo de organizaciones saludables. Para este estudio utilizaron una muestra de 62 colaboradores a los cuales se les aplico un cuestionario con siete escalas: Escala de Promoción de la Salud Organizacional, Escala de Valores Culturales en las Organizaciones, Escalas de Prácticas Saludables Organizacionales, para medir el bienestar se utilizó tres escalas para Engagement, Ansiedad y Satisfacción con el Trabajo. Los resultados que se encontraron demuestran que las acciones que busquen promover la salud tienen relación significativa y positiva 
con los valores culturales. Así mismo, las acciones de promoción de la salud dentro de la organización poseen relación significativa con la adopción de prácticas organizacionales saludables, por otro lado, los valores de la cultura organizacional no evidencian relación estadísticamente significativa con el bienestar, lo cual, podría deberse a una baja disponibilidad de apoyo emocional y una escasa participación social lo cual posee un impacto negativo en la salud y el bienestar. Por otro lado, se había demostrado la relación existente entre prácticas organizacionales saludables y el engagement, como una medida de bienestar de los trabajadores. Finalmente, concluyen indicando que los colaboradores experimentan bienestar cuando la organización lleva a cabo acciones positivas a sus trabajadores y grupos relacionados.

Vecina y Chacón (2013) en España realizaron una investigación que tuvo dos propósitos específicos, el primero fue analizar la diferencia entre engagement, compromiso organizacional y satisfacción; en segunda instancia esta investigación propone la relación entre las tres variables mencionadas y la intención de permanencia, bienestar psicológico y salud física percibida. La muestra estuvo compuesta de 257 voluntarios. Se realizó el análisis bajo tres modelos de ecuaciones estructurales cuyos resultados explican que engagement, compromiso organizacional y satisfacción son constructos diferentes. Así mismo, el engagement contribuye a explicar el compromiso, la satisfacción y el bienestar psicológicos de los voluntarios, por otro lado, el engagement no explica ni la intención de permanencia ni la salud física percibida. Concluyen que las organizaciones sin fines de lucro deben prestar atención al Engagement pues eso permitirá que los voluntarios estén más satisfechos y experimenten bienestar teniendo interés de permanecer en el trabajo.

Por otro lado, existen investigaciones que han evaluado al bienestar psicológico y engagement en relación a otras variables. 
Delgado y Velásquez (2018) realizaron una investigación en donde el objetivo principal fue hallar la influencia que tiene el engagement sobre la satisfacción laboral. La muestra estuvo compuesta por 25 colaboradores de una empresa bancaria en Arequipa. Para ello, utilizaron la Escala de UWES en donde encontraron resultados estadísticamente significativos de relación, es decir, el engagement si influye en la satisfacción laboral, por lo tanto, a mayor engagement mayor satisfacción laboral. En relación al sexo los hombres poseen un nivel ligeramente más alto que las mujeres.

Otra investigación fue realizada por Pérez y Valderrama (2018) en este estudio se buscó la relación entre estilos de liderazgo, felicidad y engagement. La muestra que utilizaron estuvo compuesta por 170 operarios y directivos de una empresa pública, a ellos se les aplico la Escala UWES, el Cuestionario CELID-A y la Escala de la Felicidad de Reynaldo Alarcón. Los resultados que se obtuvieron demuestran que existe relación positiva entre liderazgo transformacional y vigor dimensión del engagement, así como el carisma se relaciona a engagement. Por otro lado, existe relación significativa entre felicidad y engagement es decir a mayor felicidad mayor engagement.

Pérez (2017) quien realizó una investigación cuyo objetivo fue determinar la relación existente entre bienestar psicológico y compromiso organizacional. Se tuvo una muestra de 105 docentes utilizando las Escalas de Sánchez Cánovas y Meyer Allen respectivamente, encontrando que existe relación significativa entre las variables mencionadas específicamente en dos factores bienestar psicológico y componente afectivo y continuidad o necesidad. Por otro lado, se obtuvo que sexo, edad y tiempo de servicio no poseen correlación significativa con el bienestar psicológico.

Monzón (2016), teniendo como variable al Bienestar psicológico, investigó si existe diferencia de este constructo en dos poblaciones diferentes, teniendo como muestra 
a 140 docentes, 70 docentes de instituciones públicas y 70 instituciones privadas, encontrando en base a la Escala de Bienestar Psicológico de Ryff que no existen características diferenciadas en estas dos poblaciones. Se ve que en la dimensión dominio del entono ambas poblaciones poseen puntuaciones altas. Estos resultados se aducen al buen clima laboral que poseen ambas instituciones y a la comunicación asertiva de los docentes, así mismo existen niveles altos en crecimiento personal, mencionando que esto se debe a que las personas están obligadas a desarrollar potencialidades para alcanzar su potencial máximo. Con respecto, a relaciones sociales, autonomía, propósito de vida y autoaceptación tampoco muestran características diferenciadas entre estas dos poblaciones.

Barrantes y Ureña (2015) realizaron una investigación que tuvo como objetivo aportar conocimiento acerca del estado del bienestar psicológico y bienestar subjetivo en estudiantes universitarios costarricenses. Se tuvo una muestra de 402 estudiantes. Para este estudio se utilizó las escalas de Bienestar Psicológico, Afectividad Positiva y Negativa y Satisfacción con la Vida, encontrando que poseían niveles elevados de bienestar psicológico, específicamente en dimensiones crecimiento personal y propósito en la vida y los niveles más bajos son autonomía y dominio del entorno, el afecto positivo predomina y existe alta satisfacción que es explicada por las variables autoaceptación, dominio del entorno, propósito en la vida.

Rodríguez, Negrón, Maldonado, Quiñones y Toledo (2015), tuvieron como objetivo encontrar la relación entre las dimensiones de bienestar psicológico y el apoyo social percibido con relación al sexo y nivel de estudio en universitarios, para ello utilizaron la escala de Ryff y el cuestionario de Apoyo Social MOS. La muestra utilizada estuvo compuesta por 768 estudiantes de pregrado y posgrado. Los resultados mostraron correlaciones de bajas a moderadas entre las Escalas de Bienestar Psicológico y las sub- 
escalas de Apoyo Social. Siendo un resultado relevante que las mujeres puntúan más alto en crecimiento personal y propósito en la vida.

Córdova (2015) investigó los niveles de engagement en los colaboradores de una industria de detergentes ubicada en Escuintla. La muestra estuvo compuesta por 69 colaboradores en un rango de edad de 18 a 45 años, la mayoría de género masculino. Se utilizó el cuestionario UWES y fue una investigación descriptiva. Los resultados obtenidos demuestran altos niveles de engagement, lo cual evidencia que la muestra total de colaboradores está dispuesta a esforzarse y comprometerse con la organización, concluyendo también que no existe diferencias estadísticamente significativas relacionadas al género.

Grueso, Gonzales y Rey (2014) investigaron la relación existente entre la cultura organizacional y el engagement. Para ello realizaron un estudio exploratorio en una organización de salud cuya muestra estuvo conformada por 62 trabajadores de la empresa. Para la variable cultura organizacional se utilizó la escala de valores culturales de 35 items inspirada en el Modelo de Hofstede y para el engagement se utilizó la escala UWES en su versión corta. Se encontró que los valores analizados de la cultura organizacional poseen relación con el engagement de los trabajadores. Así mismo, plantean que la incertidumbre es un predictor del engagement, es decir a mayor tolerancia a la incertidumbre mayor engagement. Finalmente, concluyen que lo que generaría el engagement es el valor cultural, que evidencie una cultura de apoyo a los colaboradores de la organización.

Por otro lado, Carrasco, Corte y León (2010) investigaron el engagement como recurso para optimizar la salud psicosocial en las organizaciones y prevenir el burnout y 
estrés laboral. Se enfocaron en analizar la importancia del engagement como vía para evitar la aparición del estrés en los trabajadores. Fue una revisión y aproximación teórica, la cual, tuvo como conclusión que el capital humano es lo más importante que tienen las organizaciones, por tanto, estas deben preocuparse por tener colaboradores más que comprometidos y psicológicamente sanos - bienestar psicológico - pues esto les permitirá afrontar situaciones económicas y sociales difíciles y retadoras.

Por lo explicado anteriormente, acerca del bienestar psicológico y el engagement se puede decir que ambas variables tienen alta relación con lo que plantea la psicología positiva, con respecto al bienestar psicológico se ha notado que las variables que describen las teorías estas basadas en el modelo que Seligman (2002) propone acerca de la felicidad y bienestar. En el caso del engagement, este forma parte de las dimensiones que conforman el modelo PERMA (Domínguez \& Ibarra, 2017), cuyas dimensiones son: significado, engagement, emociones positivas, compromiso y relaciones positivas descritos líneas arriba.

Es importante que las variables bienestar psicológico y engagement se estudien de forma conjunta, pues es de interés conocer si son estos los únicos aspectos que hacen que la organización funcione de tal modo que logren los objetivos planteados y la respuesta según los antecedentes descritos en esta investigación en los últimos años demuestran que existen más factores vinculados en su mayoría al capital humano.

Es por ello, que esta investigación permite abordar en un sector clave dentro de nuestra sociedad, el sector educativo; viéndolo como una empresa que permite al colaborador - factor humano - responder a las necesidades de los estudiantes que intentan formar un futuro en base a sus carreras, es por ello, que se debe entender la importancia 
de que estos colaboradores den el mejor servicio, en base a su situación laboral, es decir a si se encuentran bien (bienestar psicológico) lo cual hace que estén más que comprometidos (engagement).

En la actualidad, el capital o talento humano es la clave para el éxito de una organización, por lo que es fundamental que el colaborador sienta que existe la posibilidad de comprometerse creando vínculos emocionales- afectivos con ella.

Por ello, la importancia de esta investigación radica en que en los últimos años ha surgido gran interés por investigar los temas relacionados al ser humano y los contextos en los que se desarrolla. Uno de estos ámbitos es el contexto laboral, dado que es en este espacio donde el hombre pasa la mayor parte de su tiempo y además pone expectativas y afectos que le permiten crecer.

El campo laboral es el espacio que le permite al ser humano interactuar, socializar, comunicar y poner en práctica conocimientos adquiridos; es por ello, la importancia de investigar los temas que pueden afectar o provocar mejoras en su rendimiento, pues tendrá como resultado identificar cuáles son las variables que hacen que el colaborador sea más comprometido, este más feliz, tenga más energía lo cual podría lograr que se involucre con la organización, de tal modo que le brinde a su centro de trabajo más de lo exigido llegando a conseguir resultados organizacionales óptimos.

Durante mucho tiempo se pensó que este involucramiento y por tanto buen desempeño, está basado en el dinero como medio para satisfacer las necesidades que proporcionan tranquilidad y bienestar a una persona (Díaz, Rodríguez-Carvajal, Blanco, Moreno-Jiménez, Gallardo, Valle \& Van Dierendonck, 2006); sin embargo, con el pasar de los años y amplias investigaciones se ha encontrado que existen factores que van más allá de una recompensa extrínseca y que más bien aquello que causa resultados 
positivos en el ser humano son variables intrínsecas, con ello no se puede limitar la importancia que tienen los bienes materiales, sin embargo existen otros factores que lo reemplazan a nivel de importancia como el sentirse a gusto con el trabajo, como un buen trato por parte del jefe, reconocimientos emocionales o la valoración de su trabajo entre otros, todo esto provoca un estado positivo en el ser humano. Siendo todo ello parte fundamental para crear organizaciones saludables.

Por ello, entendemos que comprender el aspecto sociocultural de las organizaciones es una responsabilidad que las personas encargadas de gestionarlas deben asumir, pues parte importante es entender la relación existente entre los individuos sus actitudes, expectativas y aspiraciones y la organización.

Al asumir dicha responsabilidad se preocupan por encontrar qué hace que los colaboradores estén bien y esto suele relacionarse con calidad de vida, pues diversas investigaciones demuestran que el factor clave es el bienestar psicológico de los trabajadores (Duro, 2013). En ese sentido, investigar el bienestar psicológico en el centro de trabajo y sus implicancias en el engagement nos ayudara a identificar si existe relación que permita generar herramientas para las organizaciones y de ese modo alcancen y superen objetivos organizacionales.

Asimismo, la necesidad de entender que estamos en un mundo en constante cambio y las organizaciones también están sujetos a estas varianzas, por lo que deben adaptarse a nuevas realidades y generaciones que hoy en día buscan condiciones laborales diferentes en la sociedad lo que hace que la organización se adapte a personas cuyas principales características demuestran según Rodil (2012) que poseen grandes expectativas, no piden permiso para actuar, son autónomos y buscan inmediatez, no asumen un empleo para toda la vida pues su preocupan por su estado físico, mental y 
emocional.

Todo ello provocará que la organización realice un esfuerzo extra para lograr encontrar cuales son los factores que los mantendrán comprometidos, pero sobre todo involucrados - engagement - siendo el bienestar psicológico un término clave.

En resumen, la importancia de investigar estas variables radica en que no existe gran cantidad de investigaciones que vinculen ambos constructos y que además sean estudiados en el campo educativo tomando una universidad como contexto de estudio, siendo esta también una empresa u organización que se encarga de brindar servicios a estudiantes.

Además, según el marco teórico explicado la presente investigación genera un impacto trascendental que marcaría un camino de estudio en el ámbito de recursos humanos y sobre todo en el rubro educativo, de donde se obtendrá la muestra motivando a más personas a seguir interesándose por aspectos de salud - bienestar psicológico en el ámbito educativo como generador de engagement y que a

Finalmente, los resultados obtenidos en esta investigación llevarán a la toma de decisiones dentro del contexto en donde se está aplicando el estudio pues, la actividad laboral es uno de los aspectos más importantes que el ser humano practica en su vida; por ello, la importancia de estudiar diversos temas en este campo, ya que forma parte fundamental de la calidad de vida y que además podría provocar una mejora en el desempeño, y llevaría a tener una sociedad con organizaciones más exitosas.

Después de haber detallado los aportes de estas variables se plantea la pregunta de investigación ¿Existe relación entre las dimensiones del bienestar psicológico y el engagement en una universidad privada de Lima Metropolita? 


\section{Objetivo general:}

Determinar la relación existente entre las dimensiones del bienestar psicológico y el engagement en colaboradores de una universidad privada de Lima metropolitana.

\section{Objetivos específicos:}

- Establecer la relación que tienen las dimensiones del bienestar psicológico y la dedicación en colaboradores de una universidad privada de Lima metropolitana.

- Establecer la relación que tienen las dimensiones del bienestar psicológico y el vigor en colaboradores de una universidad privada de Lima metropolitana.

- Establecer la relación que tienen las dimensiones del bienestar psicológico y la absorción en colaboradores de una universidad privada de Lima metropolitana.

\section{Hipótesis general:}

- Existe relación entre las dimensiones del bienestar psicológico y el engagement en colaboradores de una universidad privada de Lima metropolitana.

\section{Hipótesis específicas:}

- H1: Las dimensiones del bienestar psicológico tienen relación con la dedicación en colaboradores de una universidad privada de Lima metropolitana.

- H2: Las dimensiones del bienestar psicológico tienen relación con el vigor en colaboradores de una universidad privada de Lima metropolitana.

- H3: Las dimensiones del bienestar psicológico tienen relación sobre la absorción en colaboradores de una universidad privada de Lima metropolitana. 


\section{Método}

\section{Tipo y diseño de investigación}

La presente investigación es de tipo no experimental, dado que no se manipulan las variables de estudio; sólo se procede a observar la situación existente para luego analizarla a posteriori. El enfoque es cuantitativo puesto que plantea relacionar las variables en cuestión, con la finalidad de llegar a proposiciones precisas y poder emitir recomendaciones específicas (Hernández, Fernández \& Baptista, 2014).

Asimismo, es de corte transversal debido a que la recolección de datos se realiza dentro de un periodo determinado de tiempo dado.

En cuanto al diseño de investigación es correlacional, puesto que pretende determinar el grado de asociación que existe entre dos o más conceptos, categorías o variables en una muestra o contexto particular. Para evaluar el grado de asociación entre dichas variables, se mide inicialmente cada variable y posteriormente se procede a cuantificarlas y establecer las vinculaciones necesarias (Hernández et al., 2014).

\section{Participantes}

La muestra obtenida pertenece a la plana administrativa de una universidad privada de Lima Metropolitana de género tanto femenino como masculino. Para hallar esta muestra se realizó un muestreo no probabilístico por conveniencia, pues todos los que conforman la muestra han sido elegidos por su fácil accesibilidad (Hernández et al., 2014) dando como resultado un tamaño muestral de 92 participantes pertenecientes a una universidad privada de Lima Metropolitana bajo un rango de edad que fluctúa de 20 a 50 años.

Criterios de inclusión 
- Colaboradores que se encuentren estudiando y/o hayan realizado una carrera técnica o universitaria.

- Edades que fluctúen en un rango de 20 a 50 años.

Criterios de exclusión

- Colaboradores que no pertenezcan a la planilla directa de la universidad.

- Colaboradores con edades fuera del rango establecido anteriormente.

En la tabla 2 se muestran datos estadísticos referidos a la muestra. En cuanto al género, los datos refieren que el $54.6 \%$ de los participantes es de género masculino y el $55.4 \%$ pertenecen al género femenino. Por otro lado, los datos sobre el tiempo de trabajo actual, reportan que un $30.4 \%$ están laborando de entre 1 a 2 años, un $37 \%$ lleva trabajando más de 2 años y $32.6 \%$ trabaja menos de 1 año. En cuanto al nivel de formación $78.3 \%$ cuentan con estudio superior y $21.7 \%$ estudios técnicos.

Tabla 2

Descripción demográfica de la muestra.

\begin{tabular}{|c|c|c|c|c|c|}
\hline & $\mathrm{N}$ & $\%$ & & $\mathrm{~N}$ & $\%$ \\
\hline \multicolumn{2}{|l|}{ Sexo } & \multicolumn{4}{|c|}{ Nivel de Formación } \\
\hline Masculino & 41 & $54 ., 6$ & Superior & 72 & 78.3 \\
\hline Femenino & 51 & 55.4 & Técnico & 20 & 21,7 \\
\hline \multicolumn{6}{|l|}{ Tiempo de trabajo } \\
\hline De 1 a 2 años & 28 & 30,4 & & & \\
\hline Mas de 2 Años & 34 & 37 & & & \\
\hline Menos de 1 año & 30 & 32.6 & & & \\
\hline
\end{tabular}




\section{Instrumentos de medición}

Los instrumentos que se utilizarán para determinar si existe relación entre el bienestar psicológico y el engagement Laboral son la Escala de Bienestar Psicológico de Ryff, adaptación española Pérez, M. (2017) y la escala UWES de Wilmar Schaufeli Hernández, (2017).

La Escala de Bienestar Psicológico de Ryff elaborada por Carol Ryff en el año 1995 y adaptada al español por Díaz et al. (2006) fue adaptada en Perú por Pérez (2017). El instrumento determina el nivel de bienestar psicológico mediante una escala. Está compuesta por seis dimensiones: dominio del entorno, crecimiento personal, propósito en la vida, autonomía, autoaceptación y relaciones positivas con otros. El instrumento cuenta 35 ítems cuya puntuación es del 1 al 6 en escala Likert, en la que 1 es totalmente en desacuerdo; 2, Poco de acuerdo; 3, moderadamente de acuerdo; 4, muy de acuerdo;5, bastante de acuerdo y 6 es totalmente de acuerdo. En cuanto a la confiabilidad de este instrumento se midió en base al coeficiente de alfa de Cronbach cuya consistencia interna fue 0.94 con respecto a la validez se obtuvo V de Aiken de 0.91 .

La Escala UWES - The Utrecht Work Engagement Scale de Wilmar Schaufeli (2011) adaptada a Perú por Hernández (2017). El instrumento tiene como objetivo identificar el nivel de engagement en los trabajadores como también identificar el nivel de sus dimensiones. Está compuesta por tres dimensiones: vigor, absorción y dedicación. Esta escala está conformada por 17 ítems cuya puntuación es de 0 a 6 en escala de Likert; en donde 0 es nunca, 1 casi nunca, 2 algunas veces, 3 regularmente, 4 bastantes veces, 5 casi siempre y 6 es siempre. La confiabilidad del instrumento fue de 0.87 en el coeficiente Alfa de Cronbach y la validez se realizó mediante la prueba de KMO siendo adecuada en un 0,72 . 


\section{Procedimiento}

En primera instancia, se realizaron las coordinaciones y contacto con el jefe de recursos humanos de una empresa del sector educativo y se le solicito el permiso respectivo. Se pactaron las fechas intervalo en las cuales serían aplicadas las evaluaciones por medio virtual. Llegado el periodo acordado se explicó en cada área de manera verbal, los objetivos, importancia del presente estudio, contenido del link y utilizando un mensaje comprensivo se explicó de qué trata cada escala del presente estudio (escalas de evaluación para engagement y bienestar psicológico), se mencionó que la aplicación era anónima y los resultados serían globales a fin de solicitar su consentimiento. Posterior a ello, se envió el link virtual a todos los colaboradores para la aplicación de las evaluaciones que se realizaron dentro del campus estudiantil. Dichas aplicaciones se realizaron a toda la muestra y fue voluntaria.

Para los fines del presente estudio, se consideró en las aplicaciones de las pruebas los datos personales y sociodemográficos de los colaboradores de la empresa mencionada. Asimismo, se acordó con el área de recursos humanos entregar al término de la investigación un informe general sobre los resultados del estudio asegurando la confidencialidad de los datos y el anonimato de los colaboradores.

Finalmente, con los datos obtenidos se realizó la interpretación de los resultados y se planteó las conclusiones de la investigación.

\section{Análisis de datos}

A fin de analizar los datos se utilizará el paquete estadístico Statistical Package for the Social Sciences (SPSS) versión 22.

En principio se realizó la confiabilidad de los puntajes de los instrumentos, mediante el coeficiente Alfa de Cronbach, el cual es un indicador de la consistencia 
interna de los puntajes (Domínguez \& Merino, 2015). El nivel de confiabilidad mínimo que cada puntaje debía de cumplir se estableció en 0.70 .

Luego de obtener niveles aceptables de confiabilidad, se procedió con los objetivos de la investigación. Para ello, se utilizó el estadístico R de Pearson, el nivel de significancia mínimo fue 0.05 .

Para la interpretación de las correlaciones obtenidas primero se inició con la significancia estadística; únicamente si la correlación era estadísticamente significativa, se interpretaba.

La interpretación de las correlaciones se enfocó en dos aspectos la significancia estadística y los niveles de correlación mediante lo planteado por Cohen $(1988,1992)$ que refiere que será trivial si es menor a 0.20 , pequeño si es mayor o igual a 0.20 , moderado si es mayor o igual a 0.50 y grande si es mayor o igual a 0.80 . 


\section{Resultados}

En esta parte de la investigación se presentarán los hallazgos del estudio. Se inicia con la presentación de las características psicométricas principales de los instrumentos utilizados y se continúa con los resultados que responden a los objetivos de investigación previamente planteados.

\section{Confiabilidad de los instrumentos}

En la tabla 4, para el análisis de confiabilidad de las pruebas utilizadas, se halló el alfa de Cronbach siguiendo el modelo de consistencia interna.

La escala de Utrecht Work Engagement obtuvo en todos los dominios niveles estadísticamente significativos en donde vigor puntúa 0.90, dedicación 0.94 y absorción 0.76 .

Por otro lado, en la escala de bienestar psicológico de Ryff la dimensión autoaceptación inicialmente tenía 7 ítems y se obtuvo un alfa de Cronbach de 0.743, por lo que se eliminó el ítem número 5 de esa dimensión, con lo que se mejoró la confiabilidad a un 0.828 ; en cuanto a la dimensión autonomía se obtuvo un nivel de 0.766 y las dimensiones relaciones positivas, dominio del entorno, propósito de vida, y crecimiento personal alcanzaron niveles superiores a 0.80 .

En la tabla 3, de manera general, la Escala de Bienestar Psicológico de Ryff alcanzo un coeficiente de Alfa de Cronbach de 0.96 y la Escala The Utrecht Work Engagement - UWES alcanzo un coeficiente de Alfa de Cronbach de 0.94. 
Tabla 3

Análisis de fiabilidad de las escalas usadas.

Alfa de Cronbach Nro. de ítems

$\begin{array}{lll}\text { Escala de bienestar psicológico de Ryff } & 0.96 & 35\end{array}$

The Utrecht Work Engagement Scale -

UWES

0.94

17

Tabla 4

Análisis de fiabilidad de los puntajes de los instrumentos usados.

$\begin{array}{cc}\text { Alfa de } & \text { Nro. de } \\ \text { Cronbach } & \text { ítems }\end{array}$

Escala de bienestar psicológico de Ryff

Autoaceptación

$0.828 \quad 7$

Relaciones Positivas

0.814

6

Autonomía

0.766

4

Dominio del Entorno

0.828

6

Propósito de Vida

0.917

8

Crecimiento Personal

0.837

4

The Utrecht Work Engagement Scale - UWES

Dedicación

0.944

5

Absorción

0.765

6

Vigor

0.902

6 


\section{Análisis descriptivos}

En la tabla 5 se muestran los estadísticos descriptivos de las puntuaciones obtenidas de cada escala. La escala de Bienestar Psicológico de Ryff muestra una asimetría negativa en todas sus dimensiones, y una curva normal a excepción de dos dimensiones autoaceptación y propósito de vida.

La escala UWES, posee una simetría negativa con una curva normal a excepción de la dimensión absorción.

Dado los resultados las estimaciones se realizaron mediante estadísticos paramétricos; es decir, para calcular las correlaciones se empleó la correlación de Pearson.

Tabla 5

Análisis descriptivos de los puntajes de los instrumentos usados.

M DE $\quad$ Mín. $\quad$ Máx. Asimetría

\section{Escala de Ryff}

Autoaceptación

25.67

3.72

12

30

$-13.06$

Relaciones

Positivas

30.35

4.05

16

36

$-0.899$

Autonomía

19.76

3.14

12

24

$-0.674$

Dominio del

Entorno

29.90

4.50

17

36

$-0.759$

Propósito de Vida

35.25

5.74

13

42

$-1.084$

Crecimiento

Personal

20.99

3.05

12

24

$-1.064$ 


\section{UWES}

\begin{tabular}{lllccc} 
Dedicación & 24.30 & 5.86 & 8 & 30 & -1.232 \\
Absorción & 24.62 & 5.74 & 13 & 34 & -0.147 \\
Vigor & 28.14 & 5.99 & 12 & 36 & -0.844 \\
\hline $\mathrm{N}=92$ & & & & &
\end{tabular}

\section{Contraste de hipótesis}

Con respecto a la hipótesis principal de esta investigación los resultados de correlación se muestran en la tabla 6. Se realizó la correlación entre las dimensiones de la escala de Bienestar Psicológico y la escala del Engagement UWES. La tabla 6 muestra que las seis dimensiones de la escala que mide el bienestar psicológico poseen relación estadísticamente significativa con las dimensiones del engagement, específicamente con vigor.

De manera específica, autoaceptación posee relación estadísticamente significativa y pequeña con dedicación y absorción, con respecto a vigor la relación es estadísticamente significativa moderada. Por otro lado, relaciones positivas tiene relación estadísticamente significativa pequeña con absorción y con dedicación con vigor la relación es estadísticamente significativa moderada.

Así mismo, autonomía tiene relación estadísticamente significativa y pequeña con dedicación y absorción, con vigor la relación es estadísticamente significativa moderada.

Con respecto a dominio del entorno la relación es estadísticamente significativa pequeña con absorción, con dedicación y vigor la relación es estadísticamente significativa moderada.

Al hablar de la dimensión propósito de vida, la relación es estadísticamente 
significativa pequeña con dedicación y absorción con vigor la relación es estadísticamente significativa moderada.

Finalmente, con respecto a crecimiento personal existe relación estadísticamente significativa pequeña con dedicación y absorción; sin embargo, la relación con vigor fue estadísticamente significativa moderada.

Tabla 6

Correlación de Pearson entre las dimensiones de la Escala de Bienestar Psicológico de Ryff y las dimensiones de The Utrecht Work Engagement Scale - UWES.

\begin{tabular}{|c|c|c|c|c|c|c|}
\hline & \multicolumn{6}{|c|}{ The Utrecht Work Engagement Scale - UWES } \\
\hline & \multicolumn{2}{|c|}{ Dedicación } & \multicolumn{2}{|c|}{ Absorción } & \multicolumn{2}{|c|}{ Vigor } \\
\hline & $\mathrm{R}$ & Sig. (p) & $\mathrm{r}$ & Sig. (p) & $\mathrm{R}$ & Sig. (p) \\
\hline Autoaceptación & $0.479 * *$ & 0.000 & $0.258 *$ & 0.013 & $0.521 * *$ & 0.000 \\
\hline $\begin{array}{l}\text { Relaciones } \\
\text { Positivas }\end{array}$ & $0.532 * *$ & 0.000 & $0.423 * *$ & 0.000 & $0.616^{* *}$ & 0.000 \\
\hline Autonomía & $0.411 * *$ & 0.000 & $0.305^{* *}$ & 0.003 & $0.539 * *$ & 0.000 \\
\hline $\begin{array}{l}\text { Dominio del } \\
\text { Entorno }\end{array}$ & $0.531 * *$ & 0.000 & $0.283 * *$ & 0.006 & $0.623 * *$ & 0.000 \\
\hline $\begin{array}{l}\text { Propósito de } \\
\text { Vida }\end{array}$ & $0.457 * *$ & 0.000 & $0.260 *$ & 0.012 & $0.558 * *$ & 0.000 \\
\hline $\begin{array}{l}\text { Crecimiento } \\
\text { Personal }\end{array}$ & $0.438 * *$ & 0.000 & $0.244 *$ & 0.019 & $0.508 * *$ & 0.000 \\
\hline
\end{tabular}

\section{Otros resultados}

\section{Correlación entre las variables}

En la tabla 7 se puede observar que existe correlación estadísticamente 
significativa y moderada entre los totales de las variables bienestar psicológico y engagement con una $\mathrm{r}<0.05, \mathrm{p}=0.00$.

Tabla 7

Correlación de Pearson entre la Escala de Bienestar Psicológico de Ryff y The Utrecht Work Engagement Scale - UWES.

Escala de Bienestar Psicológico de Ryff

\begin{tabular}{lcc}
\cline { 2 - 3 } & $\mathrm{r}$ & Sig.(p) \\
\hline The Utrecht Work Engagement Scale - & $0.539 * *$ & 0.000 \\
**. La correlación es significativa en el nivel 0,01 (bilateral). &
\end{tabular}

En la tabla 8 se observa que existe correlación estadísticamente significativa moderada entre bienestar psicológico y las dimensiones del engagement: vigor y dedicación, mientras que con respecto a absorción existe significancia estadística pequeña. De manera detallada existe correlación $\mathrm{r}$ de 0.524 entre bienestar psicológico y dedicación, en cuanto a absorción y bienestar psicológico existe un $\mathrm{r}$ de 0.324 con una significancia de 0.02 y finalmente entre vigor y bienestar psicológico existe relación de 0.620 .

Tabla 8

Correlación de Pearson entre la Escala de Bienestar Psicológico de Ryff y las dimensiones de The Utrecht Work Engagement Scale - UWES.

\begin{tabular}{lcc}
\hline & \multicolumn{2}{c}{ Escala de Bienestar Psicológico de Ryff } \\
\cline { 2 - 3 } & $\mathrm{R}$ & Sig.(p) \\
\hline Dedicación & $0.524^{* *}$ & 0.00 \\
Absorción & $0.324^{* *}$ & 0.02 \\
Vigor & $0.620^{* *}$ & 0.00 \\
\hline **. La correlación es significativa en el nivel 0,01 (bilateral).
\end{tabular}




\section{Discusión}

La presente investigación tuvo como objetivo determinar la relación que existe entre las dimensiones del bienestar psicológico y engagement en colaboradores de una universidad privada de Lima Metropolitana. Para ello se trabajó con una muestra de 92 colaboradores y se emplearon las escalas de Bienestar Psicológico de Carol Ryff y la escala The Utrecht Work Engagement - UWES.

En cuanto a los resultados se encontró que se acepta la hipótesis de investigación, ya que sí existe relación entre las dimensiones del bienestar psicológico y engagement en colaboradores de una universidad privada de Lima Metropolitana. Es así que nuestros resultados coinciden con los de Amasifuén (2016) quien investigo acerca del bienestar psicológico e involucramiento laboral, esta última fue medida con la escala que se utiliza para medir el engagement.

Sin embargo, al hablar de correlaciones entre dimensiones encontramos que la investigación realizada por Zulueta (2019); no apoya nuestros hallazgos pues en una muestra de profesionales de enfermería de cuidados paliativos, se obtuvo que dedicación es la dimensión que mejor explica la escala engagement; mientras que la presente investigación muestra que vigor es la dimensión que mejor explica el engagement.

Como se mencionó, se encontró que la variable bienestar psicológico se relaciona significativamente con las dimensiones del engagement, específicamente con el vigor, el cual es descrito como el deseo intrínseco que posee el colaborador por dar más de lo esperado, y además está relacionado a altos niveles de energía y resistencia mental a diversas situaciones de conflicto Delgado y Velasquez (2018). Esto se refuerza en lo planteado por Carrasco, Corte y León (2010) quienes investigaron al engagement como el recurso que optimiza la salud psicosocial de colaboradores, es decir previene el burnout 
y estrés laboral. Concluyendo, que lo más importante dentro de una organización es el capital humano y es por ello que deben preocuparse en generar acciones que los mantengan más que comprometidos y psicológicamente sanos - bienestar psicológico pues esto les permitirá afrontar situaciones económicas y sociales difíciles y retadoras, para lo cual necesitaran altos niveles de vigor tal y como se muestra en esta investigación.

Así mismo, la relación significativa entre la variable bienestar psicológico y engagement, se apoya en lo expuesto por Pérez (2017) cuya investigación se enfocó en determinar si existe relación entre bienestar psicológico y compromiso. Si bien las escalas usadas difieren de nuestra investigación, el contexto de donde se sacó la muestra es similar. Por lo que se toma en consideración los resultados que demuestran que existe relación significativa entre las variables mencionadas básicamente en dos factores bienestar psicológico y componente afectivo y continuidad o necesidad, cuyo resultado puede significar que el bienestar de los colaboradores está relacionado a los sentimientos hacia su organización y a la necesidad de permanecer en ella (Figueroa, 2016).

Es importante, mencionar también que la relación significativa de nuestras variables puede ser opuesta a lo explicado por Grueso et al. (2013) quienes bajo un modelo de organizaciones saludables buscaron describir las acciones de promoción de la salud organizacional y su relación con variables estructurales y el bienestar de los trabajadores asumiendo que el engagement es una variable que promueve el bienestar. Los resultados demostraron que los colaboradores experimentan bienestar cuando la organización lleva a cabo acciones positivas dirigidas a sus colaboradores y grupos relacionados. Además, existe relación entre prácticas organizacionales saludables y el engagement, funcionando este como una medida de bienestar de los trabajadores. Contrariamente, a lo que nosotros pretendemos demostrar en esta investigación pues tratamos al bienestar psicológico como un causante de engagement. 
Así mismo, otro de los resultados obtenidos dentro de este estudio refiere que las subescalas del bienestar psicológico, dominio del entorno y relaciones positivas explican a la subescala dedicación. Es decir, la razón por la que los colaboradores sienten que su trabajo posee un significado, se entusiasman, enorgullecen y vinculan con sus funciones, relacionándolo con el reto que frecuentemente representa su jornada laboral (Salanova \& Schaufeli, 2004), se debe a que posee confianza en el manejo del entorno y generan relaciones positivas de confianza con otros (Meneses et al., 2016).

Esto es apoyado en lo que plantean Jena, Pradhan y Panigrahy (2018) quienes identifican el efecto directo del engagement del colaborador en la confianza de la organización y, en segundo lugar, investigar el efecto indirecto del bienestar psicológico y el liderazgo transformacional en la relación entre el engagement de los trabajadores y la confianza de la organización. En base a las escalas de ejecutivos de Utrecht Work Engagement (UWES) y la Escala de Bienestar Psicológico de Ryff encontraron que si la organización tiene líderes que comparten objetivos y que demuestren ética y confianza en diversos aspectos (comunicación, relaciones, manejo del entorno) se generará un ambiente de trabajo más atractivo en donde el colaborador sienta que es considerado dentro de su entorno, generando colaboradores engaged y por consecuencia estos mismos colaboradores poseen altos niveles en las dimensiones del bienestar psicológico.

Esto último también se apoya en lo planteado por Grueso et al. (2014), quienes encontraron lo que generaría el engagement es el valor cultural, es decir que una empresa evidencie apoyo, confianza, ética hacia los colaboradores de la organización.

Siguiendo con esta línea, los resultados de esta investigación dan a notar la importancia que tiene el contexto organizacional, lo cual es apoyado en lo planteado por Monzón (2016) que, teniendo como variable al bienestar psicológico, investigó si existe 
diferencia de este constructo en dos poblaciones diferentes. Utilizó la Escala de Bienestar Psicológico de Ryff, encontrando que la dimensión dominio del entono posee puntuaciones altas en ambas poblaciones, lo cual adujo al buen clima laboral que poseen ambas instituciones y a la comunicación asertiva. Esto apoya los resultados obtenidos en la presente investigación, pues es la sub escala dominio del entorno la que mejor explica al vigor, relacionado a altos niveles de energía y resistencia mental, durante el periodo o jornada laboral Delgado y Velasquez (2018).

Dentro de las dimensiones del bienestar psicológico, existen dos que han sido objeto de evaluación en diversas investigaciones: crecimiento profesional y propósito de vida. En la presente investigación ambas poseen niveles estadísticamente significativos de relación a las dimensiones del engagement. Esto se confirma con lo que menciona Barrantes y Ureña (2015) cuya investigación tuvo como objetivo aportar conocimiento acerca del estado del bienestar psicológico y bienestar subjetivo, encontrando que poseían niveles elevados de bienestar psicológico, específicamente en dimensiones crecimiento personal y propósito en la vida, esto puede debe ser explicado por Perán (2014) quien afirma después de su revisión teórica, que el ser humano posee dimensiones orientadas al crecimiento, a las relaciones interpersonales y el propósito de vida.

Lo cual se debe a la necesidad del ser humano por estar inmerso a un proceso de cambio y aprendizaje constante, donde la persona debe desarrollar su potencial y darle significado a su vida con el objetivo de crecer y lograr el desarrollo de sus capacidades. Así mismo, Rodríguez et al. (2015) intentaron investigar las dimensiones del bienestar psicológico y apoyo social percibido con relación al sexo y nivel de estudio en universitarios. Si bien no encontraron resultados significativos entre las variables, algo que resaltar es que las mujeres puntúan más alto en crecimiento personal y propósito en la vida a diferencia de los varones. 
Con respecto al engagement los resultados evidencian que sus dimensiones poseen niveles de correlación significativas al bienestar psicológico. Esto se apoya en lo mencionado por Córdova (2015) quien a través de una investigación descriptiva intentó estudiar los niveles de engagement en una muestra con edades entre 18 a 45 años, teniendo como resultados altos niveles de engagement, lo cual describe que colaboradores están dispuestos a esforzarse y comprometerse con la organización. Siendo esto resultado de lo que Grueso et al. (2014), explican en su investigación acerca de los valores de la cultura organizacional y su relación con el engagement, pues encontraron que el colaborador engaged es aquel que percibe evidencia de una cultura de apoyo a los colaboradores de la organización esto es lo que generaría el engagement.

Por lo mencionado antes, la presente investigación representa un aporte en cuanto a la línea de estudio de las universidades como un contexto organizacional, que puede o no ser favorecedora de bienestar psicológico y engagement, radicando en este punto la importancia de los hallazgos; pues, si los colaboradores alinean sus metas personales a los de la organización, dicha empresa crecerá por los esfuerzos de cada trabajador (Lope, Reyna \& Hernández, 2013).

En cuanto a las limitaciones del estudio detallamos dos aspectos. El primero de ellos es la dificultad para poder acceder a la muestra, dado que la empresa es una entidad que posee como política la protección de datos de sus colaboradores, lo cual nos obliga a realizar una evaluación no probabilística. Siendo esta la segunda limitación, pues al realizar un muestreo no probabilístico no podemos generalizar nuestros resultados a toda la población. Así mismo se está utilizando el constructo bienestar dentro del ámbito laboral basándonos solo en el aspecto psicológico de la teoría de Carol Ryff lo cual podría ser también un posible aspecto limitante a lo largo de la realización de este estudio. 
Otro limitante para esta investigación es la falta de investigaciones que aborden el bienestar psicológico y engagement de manera conjunta, ya que los estudios realizados tratan al engagement como compromiso siendo este un concepto diferente, lo cual dificulta el hallazgo de antecedentes más relevantes.

Así mismo, la deseabilidad social también representa un limitante, pues los colaboradores para no quedar mal con la institución podrían responder de manera positiva para obtener resultados óptimos y con ello dar a conocer que tienen una percepción positiva de la organización y lo que esta brinda.

Dentro de los aspectos éticos, el primero que se considero fue el acuerdo con la institución que permitió realizar la aplicación de las pruebas, el acuerdo fue que se enviara una réplica de los resultados obtenidos.

En segundo lugar, se ha considerado realizar el consentimiento informado dentro de la prueba virtual para validar la participación voluntaria de los colaboradores parte de la muestra.

Así mismo, siguiendo el principio ético de confidencialidad, la investigación no revela en nombre de la institución en donde ha sido realizada la evaluación, con lo que se busca proteger los datos de la entidad.

Finalmente, dentro de acuerdo con los principios éticos establecidos se consideró que la aplicación de la prueba sea de carácter anónimo para salvaguardar los datos que emiten en cada escala aplicada.

\section{Conclusiones}

- $\quad$ Existe relación estadísticamente significativa moderada entre las dimensiones bienestar psicológico y el engagement en colaboradores de una universidad privada de Lima metropolitana. 
- $\quad$ Existe relación estadísticamente significativa pequeña entre las dimensiones del bienestar psicológico y la dedicación en colaboradores de una universidad privada de Lima metropolitana.

- $\quad$ Existe relación estadísticamente significativa moderada entre las dimensiones del bienestar psicológico y el vigor en colaboradores de una universidad privada de Lima metropolitana.

- $\quad$ Existe relación estadísticamente significativa pequeña entre las dimensiones del bienestar psicológico y la absorción en colaboradores de una universidad privada de Lima metropolitana.

\section{Recomendaciones}

Al existir relación estadísticamente significativa entre las variables de estudio se recomienda poner énfasis en los factores que promueven el bienestar psicológico, pues esta variable predice el engagement; es decir, si los colaboradores perciben autoaceptación, relaciones positivas, autonomía, dominio del entorno, propósito de vida y crecimiento personal se generará engagement en ellos, provocando que se involucren, comprometan y alineen sus objetivos organizacionales con los de la empresa objeto de estudio.

Por otro lado, se recomienda a las futuras investigaciones que estudien el bienestar psicológico y engagement, dentro del ámbito educativo específicamente en universidades viéndola como una organización.

Así mismo, se recomienda realizar investigaciones con estas variables incluyendo aspectos sociodemográficos que permitan obtener resultados que evidencien si existe diferencias o similitudes entre sexos, edades, ocupaciones y/o grado académico.

Finalmente, al existir relación estadísticamente significativa entre las variables, se 
recomienda, esta investigación como punto de inicio para posibles estudios acerca de la relación entre el estado de bienestar del colaborador su nivel de engagement y estudios del desarrollo profesional de los estudiantes, involucrando a su vez variables como servicio al cliente. 


\section{Referencias}

Alandete, J. (2013). Bienestar psicológico, edad y género en universitarios españoles. Salud \& sociedad, 4(1), 48-58.

Amasifuén, C. (2016). Bienestar psicológico e involucramiento laboral en colaboradores de un organismo descentralizado de la municipalidad provincial de Trujillo 2016. (Tesis de Grado) Universidad Privada Antenor Orrego, Trujillo.

Bakker, A. \& Demerouti, E. (2013). La teoría de las demandas y los recursos laborales. Revista de Psicología del Trabajo y de las Organizaciones, 29(3), 107-115.

Barrantes, K., \& Ureña, P. (2015). Bienestar psicológico y bienestar subjetivo en estudiantes universitarios costarricenses. Revista Intercontinental de Psicología y Educación, volumen: 17(1), 101-123.

Brunstein, J. (1993). Personal goals and subjective well-being: A longitudinal study. Journal of personality and social psychology, 65(5), 1061.

Cárdenas, T. (2014). Engagement (Ilusión por el trabajo): Un modelo Teórico Conceptual. México: Red Durango de Investigadores Educativos A. C. México.

Carlin, M., \& de los Fayos, E. (2010). El síndrome de burnout: Evolución histórica desde el contexto laboral al ámbito deportivo. Anales de Psicología, 26(1), 169-180.

Carrasco, A., Corte, C., \& Lean, J. (2010). Engagement: un recurso para optimizar la salud psicosocial en las organizaciones y prevenir el burnout y estrés laboral. Revista Digital de Prevención, 1, 1-9.

Cassaretto, M., \& Martínez, P. (2017). Validación de las escalas de bienestar, de florecimiento y afectividad. Pensamiento Psicológico, 15(1), 19-31.

Casullo, M. (2002). Evaluación de bienestar psicológico en Iberoamérica. Madrid: Paidós.

Chávez, S. (2008). Bienestar psicológico en practicantes de yoga. Bienestar psicológico en practicantes de yoga (Tesis de Grado). Pontificia Universidad Católica del Perú, Lima.

Cohen, J. (1988). Statistical power analysis for the behavioral sciences (2nd ed.). Hillsdale, NJ: Erlbaum. 
Cohen, J. (1992). A power primer. Psychological Bulletin, 112, 155-159.

Córdova, N. (2015). Niveles de Engagement en los colaboradores de una industria de detergentes ubicada en Escuintla (Tesis de Grado). Universidad Rafel Landívar, México.

Corral, V. (2012). Sustentabilidad y psicología positiva. Una visión optimista de las conductas proambientales y prosociales. México: Manual Moderno.

Cuadra, H., \& Florenzano, R. (2003). El bienestar subjetivo: hacia una psicología positiva. Revista de Psicología, 12(1), 83.

Cubas, M. (2003). Bienestar subjetivo, bienestar psicológico y rendimiento académico en estudiantes universitarios (Tesis de Licenciatura). Universidad de Lima. Lima, Perú.

Definición y etimología. (2014). Definición y etimología de bienestar. Octubre 01, 2018, de E-Cultura Group Sitio web: https://definiciona.com/bienestar/

Delgado, S., \& Velásquez, K. (2018). Influencia del engagement en la satisfacción laboral de los colaboradores de una agencia bancaria en el distrito de CaymaArequipa, 2018 (Tesis de Grado). Universidad Católica San Pablo.

Díaz, D., Rodríguez-Carvajal, R., Blanco, A., Moreno-Jiménez, B., Gallardo, I., Valle, C., \& Van Dierendonck, D. (2006). Adaptación española de las escalas de bienestar psicológico de Ryff. Psicothema, 18(3), 572-577.

Domínguez, R. \& Ibarra, E. (2017). La psicología positiva: Un nuevo enfoque para el estudio de la felicidad. Razón y palabra, 21(96), 660-679.

Domínguez, S. \& Merino, C. (2015). ¿Por qué es importante reportar los intervalos de confianza del coeficiente alfa de Cronbach? RLCSNJ, 13(2).

Duro, M. (2013). Psicología de calidad de vida laboral desde la perspectiva de la Psicología del Trabajo y de las Organizaciones. Madrid: Pirámide.

Equipo Cuídemnos. (2011). Bienestar del docente: Vivir bien educando: estrategias para conseguir satisfacción profesional y personal. España: Editorial Graó.

Espinoza, J. (2017). El Engagement Laboral y su impacto en la productividad en una empresa de servicios (Tesis de Maestría). Universidad Peruana De Ciencias Aplicadas, Perú. 
Freudenberger, H. (1974). Staff burn-out. Journal of social issues, 30(1), 159-165.

García, C \& Gonzales, I. (2000). La categoría bienestar psicológico: Su relación con otras categorías sociales. Revista cubana de medicina general integral, 16, 586-592.

Garrido, A. (2006). Socio psicología del trabajo. Barcelona: Editorial UOC.

Gebauer, J., Lowman, D., \& Gordon, J. (2008). Closing the engagement gap: How great companies unlock employee potential for superior results. New York: Penguin.

Giraldo, V., \& Pico, M (2012). Engagement vínculo emocional del empleado con la organización (Bachelor's tesis). Universidad de la Sabana.

Grueso, M., Gonzales, J., \& Rey, C. (2014). Valores de la cultura organizacional y su relación con el "engagement "de los empleados: Estudio exploratorio en una organización de salud. Revista Investigación y Pensamiento Crítico, 2(3), 78-92.

Grueso, M., Rey, C., González, J., Ardila, A., \& Pineda, C. (2013). Acciones de promoción de la salud organizacional y su relación con variables estructurales y el bienestar de los trabajadores: Análisis desde un modelo de organizaciones saludables. Informes psicológicos, 13(2), 59-78.

Gutiérrez, O., Loboa, N., \& Martínez, J. (2017). Prevalencia del Síndrome de Burnout en profesionales de enfermería de la Orinoquia colombiana, 2016. Universidad y Salud, 20(1), 37-43.

Hernández, H. (2017). Compromiso Organizacional y Engagement en trabajadores del área administrativa de una empresa call center del Callao, 2017 (Tesis de Grado). Universidad Cesar Vallejo Lima, Perú.

Hernández, R. (2017). El compromiso por el trabajo en los vendedores de Saga Falabella, San Isidro (Tesis de Grado). Universidad Inca Garcilaso de la Vega. Lima.

Hernández, R., Fernández, C., \& Baptista, P. (2014). Metodología de la investigación. México, DF: Editorial McGraw.

Indacochea, M., Pincay, D., Reyes, S., García, J., \& Indacochea, B. (2018). Cultura organizacional de servicio al cliente en las entidades públicas del sector educativo. Dominio de las Ciencias, 4(1), 373-384. 
Jena, L., Pradhan, S., \& Panigrahy, N. (2018). Pursuit of organisational trust: Role of employee engagement, psychological well-being and transformational leadership. Asia Pacific Management Review, 23(3), 227-234.

Juárez, J., Hernández, I., Flores, C., \& Camacho, A. (2015). Entusiasmo Psicológico en el Trabajo en profesionales de la salud: Propiedades psicométricas de la Utrech Work Engagement Scale. En A. Juárez-García, (Ed.), Investigaciones Psicométricas de Escalas Psicosociales en Trabajadores Mexicanos (En publicación).

Kahn, W. A. (1990). Psychological conditions of personal engagement and disengagement at work. Academy of management journal, 33(4), 692-724.

Leturia, F. (2001).Valoración de las Personas Mayores: evaluar para conocer, conocer para intervenir. Española: Caritas.

Leiter, M. \& Bakker, A. B. (2010). Work engagement: A handbook of essential theory and research. Psychology press.

Levitas, R. (2007). Florecimiento humano: ¿una agenda utopista? Desacatos, 23, 87-100.

Liñán, A. (2016). Engagement Laboral: Una formación en prácticas rentable. (Tesis de Grado). Universidad de Almería, España.

Loera, N., Balcázar, P., Trejo, L., Gurrola, G., \& Bonilla, M. (2017). Adaptación de la escala de Bienestar Psicológico de Ryff en adolescentes preuniversitarios. Neurología, Neurocirugía y Psiquiatría, 41(3-4), 90-97.

Lope, L., Reyna, C., \& Hernández, F. (2013). Recursos humanos: la importancia de la motivación e incentivos para los trabajadores. Observatorio de la Economía Latinoamericana, (185).

Lupano, M., \& Castro, A. (2010). Psicología Positiva: Análisis desde su surgimiento. Prensa Médica Latinoamericana, 43-56.

Maslach, C., \& Leiter, M. P. (1997). The Truth about Burnout: How Organizations Cause Personal Stress and What to Do about It. San Francisco, CA: Jossey- Bass.

Medina, M., Gutierrez, C., \& Padros, F., (diciembre, 2013). Propiedades psicométricas de la escala de bienestar psicológico de Ryff en población mexicana. Revista Educación Desarrollo, 27, 25-30. 
Meneses, M., Sánchez, S., \& Sepúlveda, M. (2016). Revisión de las principales teorías de Bienestar Psicológico (Tesis de Licenciatura). Universidad de Antioquia.

Meza, B. (2010). Bienestar Psicológico en practicantes de danza contemporánea (Tesis de Grado). Pontificia Universidad Católica del Perú, Perú.

Montalvo, G., \& Plasencia, R. (2015). La motivación: Comportamiento Organizacional.

Monzón, K. (2016). Bienestar Psicológico en Docentes de Instituciones Educativas Públicas y Privadas del Distrito de San Juan de Lurigancho. Lima, 2016 (Tesis de Grado). Universidad Cesar Vallejo, Perú.

Oblitas, L. (2008). Psicología de la salud: Una ciencia del bienestar y la felicidad. Avances en psicología, 16(1), 9-38.

Park, N., Peterson, C., \& Sun, J. (2013). La psicología Positiva: Investigación y aplicaciones. Terapia Psicológica, 11-19.

Perán, V. (27 de marzo de 2014). Saludablemente psicología. Obtenido de Saludablemente psicología: http://saludablementepsicologia.es/2014/03/27/florecer-para-el-bienestar/

Pérez, B., \& Valderrama, A., (2018). Estilos de liderazgo, felicidad y su relación con el Engagement en una organización del Gobierno Regional de Arequipa-AutodemaMajes Siguas.

Pérez, D. (2017). Bienestar psicológico y compromiso organizacional en docentes de dos instituciones educativas públicas, Los Olivos, 2017 (Tesis de Grado). Universidad Cesar Vallejo, Perú.

Pérez, M. (2017). Adaptación de la Escala de Bienestar Psicológico de Ryff en trabajadores de empresas industriales del Distrito de Los Olivos (Tesis de Licenciatura). Universidad César Vallejo.

Ryan, M., \& Deci. L. (2000). Self-determination theory and the facilitation of intrinsic motivation, social development, and well-being. American psychologist, 55(1), 68.

Ryff, C. (1989). Happiness is everything, or is it? Explorations on the meaning of psychological well-being. Journal of personality and social psychology, 57(6), 1069. 
Ryff, C., \& Keyes, C. (1995). The structure of psychological well-being revisited. Journal of personality and social psychology, 69(4), 719.

Ryff, C., \& Singer, H. (2006). Best news yet on the six-factor model of well-being. Social Science Research, 35(4), 1103-1119.

Rodil, S. (6 de agosto de 2012). El empleo. Obtenido de El empleo: http://www.elempleo.com/co/noticias/investigacion-laboral/caracteristicas-de-lageneracion-y-4232

Rodríguez, Y., \& Quiñones, A. (2012). El bienestar psicológico en el proceso de ayuda con estudiantes universitarios. Revista Griot, 5(1), 7-16.

Rodriguez, Y., \& Berrios A. (diciembre, 2012). El bienestar psicológico en el proceso de ayuda con estudiantes universitarios. Griot, 5, 7-17.

Rodríguez, Y., Negrón, N., Maldonado, Y., Quiñones, A., \& Toledo, N. (2015). Dimensiones de bienestar psicológico y apoyo social percibido con relación al sexo y nivel de estudio en universitarios. Avances en Psicología Latinoamericana, 33(1), 31-43. doi: dx.doi.org/10.12804/apl33.01.2015.03

Salanova, M., \& Schaufeli, W. (2004). El Engagement de los empleados: un reto emergente para la dirección de los Recursos Humanos. Estudios Financieras, 109261.

Salgado, J., \& Peiro, J. (2008). Psicología del trabajo, las organizaciones y los recursos humanos en España. Papeles del psicólogo, 29(1), 2-5.

Seligman, M. (2002). La auténtica Felicidad. Barcelona: Editorial Zeta.

Seligman, M. (2016). Florecer. La nueva psicología positiva y la búsqueda del bienestar. México: Océano exprés.

Schaufeli, W., \& Bakker, A. (2003). UWES Utrecht work engagement scale. Preliminary manual, 1 .

Schaufeli, W., Salanova, M., González-Romá, V., \& Bakker, A. (2002). The measurement of engagement and burnout: A two sample confirmatory factor analytic approach. Journal of Happiness studies, 3(1), 71-92.

Significado de Engagement. (05 de junio de 2015). Obtenido de https://www.significados.com/engagement 
Thompson, I. (octubre de 2007). Promonegocios.net. Obtenido de Promonegocios.net: https://www.promonegocios.net/empresa/concepto-organizacion.html

Vecina, M., \& Chacón, F. (2013). ¿Es el engagement diferente de la satisfacción y del compromiso organizacional? Relaciones con la intención de permanencia, el bienestar psicológico y la salud física percibida en voluntarios. Canales de la Psicologìa, 225-232.

Vera, B. (2006). psicología Positiva: Una nueva forma de entender la psicología positiva. Papeles del psicólogo, 3- 8.

Vera, P., Urzua, A., Silva, J., Pávez, P., \& Celis, K. (2012). Escala de Bienestar de Ryff: Análisis Comparativo de los Modelos Teóricos en Distintos Grupos de Edad. psicología: Reflexión y Critica, 106-112.

Zamora, G. (27 de mayo de 2016). Instituto Educativo de Psicología Positiva. Obtenido de Instituto Educativo de psicología Positiva: https://cursopsicologiapositiva.com/modelo-perma/

Zulueta, E (2019). El buen cuidado en la proximidad de la muerte. Impacto del bienestar y la vinculación laboral en los profesionales de enfermería.

Zúñiga, M. (agosto de 2010). Incidencia del ejercicio físico/ deportivo sobre el bienestar psicológico (Tesis de Grado). Universidad de Aconcagua, Argentina. 


\begin{abstract}
ANEXOS
Anexo 1

Formulario de consentimento informado

Título del proyecto: Bienestar Psicológico y Engagement en colaboradores de una universidad privada de Lima Metropolitana.

Institución: Universidad San Ignacio de Loyola

Investigador: Kerly Stefanny Duran Quispe

Email: kerlydq@gmail.com
\end{abstract}

\title{
Presentación:
}

El presente es un estudio que tiene por finalidad conocer si existe relación entre las dimensiones del Bienestar Psicológico y el Engagement en una universidad privada de Lima Metropolita. Por lo cual, solicitamos su amable participación en este proceso y estaremos agradecidos si accede a el mismo. La participación consiste en responder las escalas que se presentan a continuación. El proceso es completamente anónimo y puede interrumpir su participación cuando considere pertinente sin que esto tenga repercusiones negativas para usted. Cabe mencionar que los resultados obtenidos con la presente investigación serán brindados a la organización como parte del acuerdo establecido.

Esta actividad es voluntaria y no habrá algún tipo de beneficio monetario.

Muchas gracias por su atención.

Respuesta: He leído el Formulario de Consentimiento Informado y acepto participar en esta actividad de investigación. Asimismo, comprendo que puedo interrumpir mi participación en esta actividad en cualquier momento.

También, entiendo que no recibiré algún pago o beneficio económico por esta participación. 
Anexo 2

ESCALA DE BIENESTAR PSICOLÓGICO DE RYFF

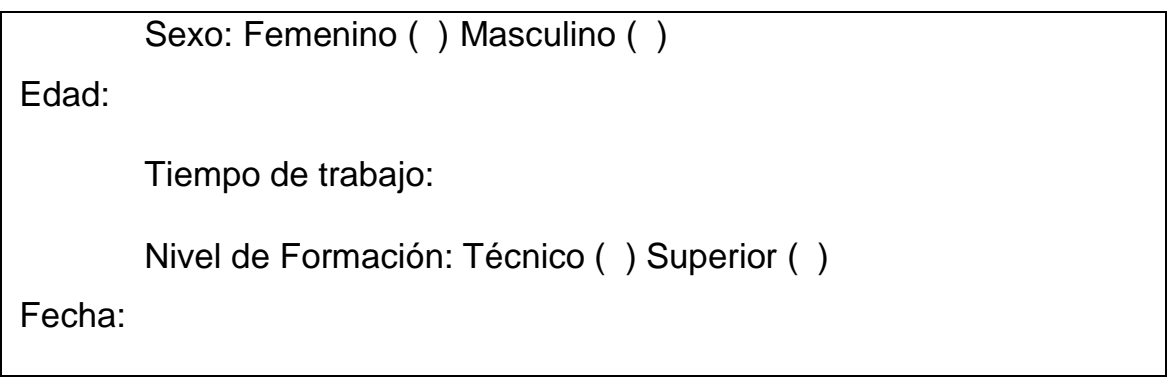

A continuación, se presenta algunos enunciados sobre el modo como usted se comporta, siente y actúa. No existe respuesta correcta o incorrecta. Responda con sinceridad. Su respuesta puede determinarlo marcando una equis $(\mathrm{x})$.

\begin{tabular}{|c|c|c|c|c|c|}
\hline $\begin{array}{c}\text { Totalmente } \\
\text { desacuerdo }\end{array}$ & $\begin{array}{c}\text { Poco de } \\
\text { acuerdo }\end{array}$ & $\begin{array}{c}\text { Moderadamente } \\
\text { de acuerdo }\end{array}$ & $\begin{array}{c}\text { Muy de } \\
\text { acuerdo }\end{array}$ & $\begin{array}{c}\text { Bastante de } \\
\text { acuerdo }\end{array}$ & $\begin{array}{c}\text { Totalmente de } \\
\text { acuerdo }\end{array}$ \\
\hline
\end{tabular}

\begin{tabular}{|c|c|c|c|c|c|c|}
\hline Ítems & 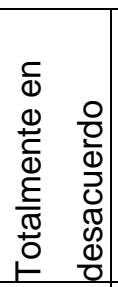 & $\begin{array}{l}\text { 음 } \\
\frac{0}{0} \\
0 \\
\pi \\
0 \\
0 \\
0 \\
0 \\
0 \\
0\end{array}$ & 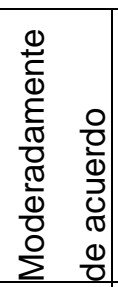 & $\begin{array}{l}0 \\
0 \\
0 \\
0 \\
0 \\
0 \\
0 \\
0 \\
3 \\
3\end{array}$ & 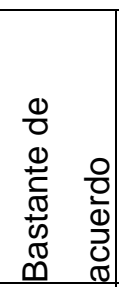 & 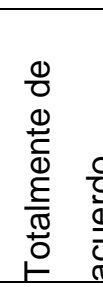 \\
\hline $\begin{array}{l}\text { 1. Cuando repaso la historia de mi vida estoy } \\
\text { contento con cómo han resultado las cosas }\end{array}$ & & & & & & \\
\hline $\begin{array}{l}\text { 2. Siento que mis amistades me aportan muchas } \\
\text { cosas }\end{array}$ & & & & & & \\
\hline $\begin{array}{l}\text { 3. No tengo miedo de expresar mis opiniones, } \\
\text { incluso cuando son opuestas a las opiniones de la } \\
\text { mayoría de la gente. }\end{array}$ & & & & & & \\
\hline $\begin{array}{l}\text { 4. En general, con el tiempo siento que sigo } \\
\text { aprendiendo más sobre mí mismo }\end{array}$ & & & & & & \\
\hline $\begin{array}{l}\text { 5. Tengo confianza en mis opiniones incluso si son } \\
\text { contrarias al consenso general. }\end{array}$ & & & & & & \\
\hline
\end{tabular}




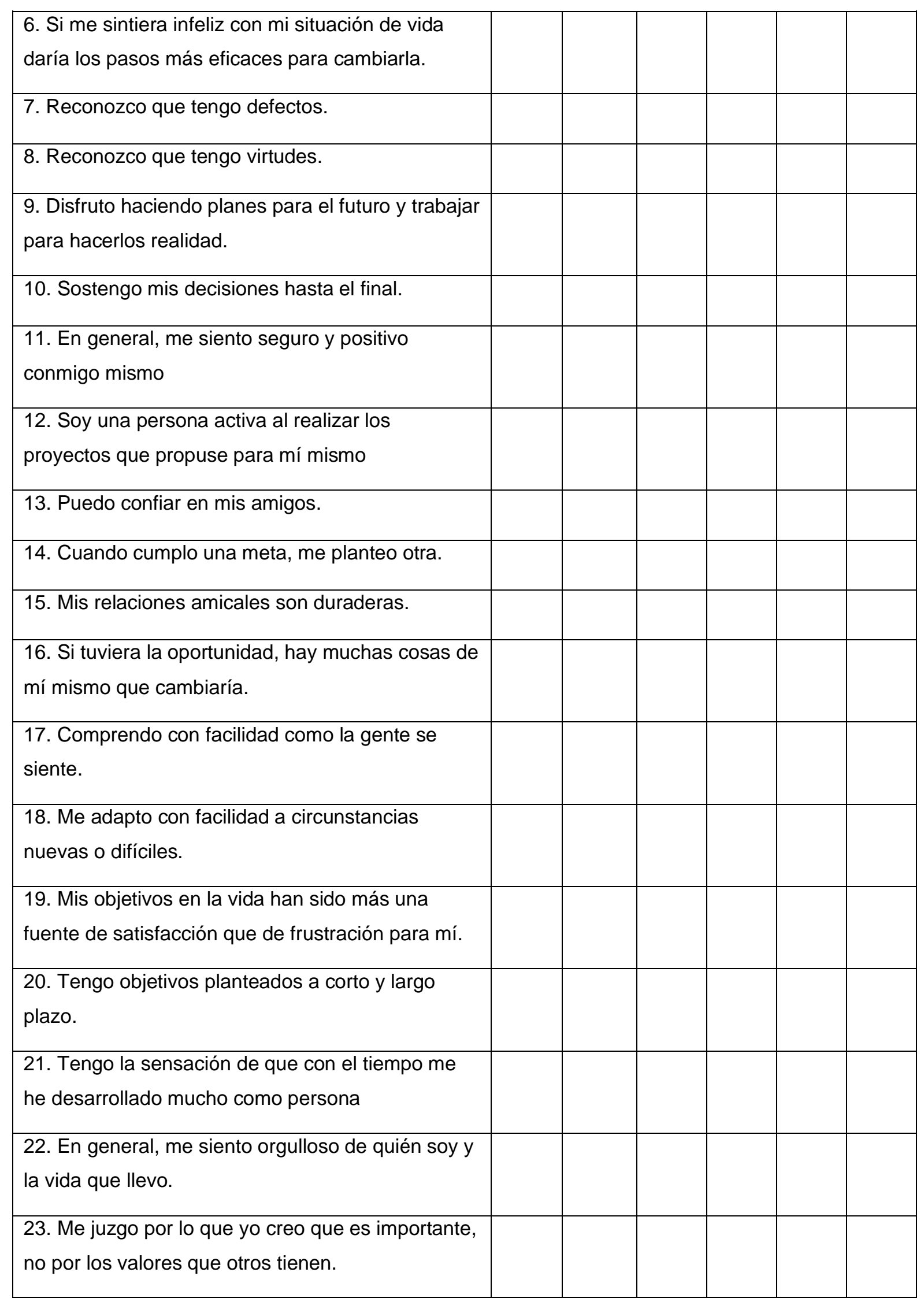




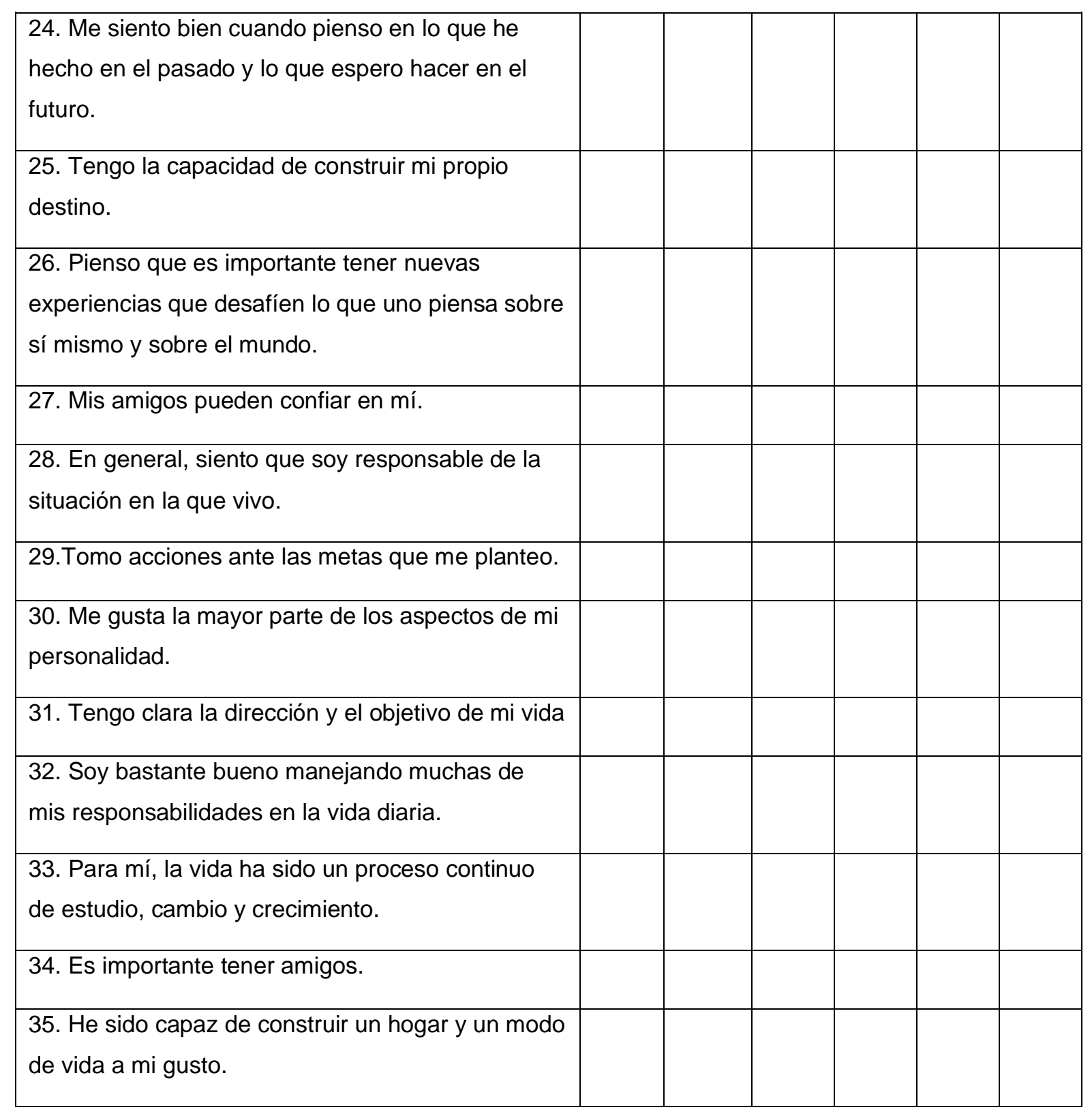




\section{Anexo 3}

\section{Cuestionario UWES -17}

\begin{tabular}{|lc|}
\hline Sexo: Femenino ( ) Masculino ( ) & Edad: \\
Tiempo de trabajo: & \\
Nivel de Formación: Técnico ( ) Superior ( ) & Fecha: \\
\hline
\end{tabular}

A continuación, hay algunas afirmaciones respecto a los sentimientos que le provocan su trabajo. Piense con qué frecuencia le surgen a usted esas ideas o con qué frecuencia las siente, teniendo en cuenta la escala que se le presenta a continuación.

\begin{tabular}{|c|c|c|c|c|c|c|}
\hline Nunca & Casi nunca & $\begin{array}{c}\text { Algunas } \\
\text { veces }\end{array}$ & $\begin{array}{c}\text { Regularment } \\
\text { e }\end{array}$ & $\begin{array}{c}\text { Bastante } \\
\text { s veces }\end{array}$ & $\begin{array}{c}\text { Casi } \\
\text { siempre }\end{array}$ & Siempre \\
\hline 0 & 1 & 2 & 3 & 4 & 5 & 6 \\
Ninguna & Pocas & Una vez al & Pocas veces & Una vez & Pocas & Todos los \\
vez & veces al & mes o & al & por & veces & días \\
& año & menos & mes & semana & por semana & \\
\hline
\end{tabular}

\begin{tabular}{|l|l|l|}
\hline 1 & En mi trabajo me siento lleno de energía. (VI1)* & \\
\hline 2 & Mi trabajo está lleno de significado y propósito. (DE1) & \\
\hline 3 & El tiempo vuela cuando estoy trabajando. (AB1) & \\
\hline 4 & Soy fuerte y vigoroso en mi trabajo. (VI2)* & \\
\hline 5 & Estoy entusiasmado con mi trabajo. (DE2)* & \\
\hline 6 & Cuando estoy trabajando olvido todo lo que pasa alrededor de mi. (AB2) & \\
\hline 7 & Mi trabajo me inspira. (DE3) & \\
\hline 8 & Cuando me levanto por las mañanas tengo ganas de ir a trabajar. (VI3)* & \\
\hline 9 & Soy feliz cuando estoy absorto en mi trabajo. (AB3) & \\
\hline 10 & Estoy orgulloso del trabajo que hago. (DE4) & \\
\hline 11 & Estoy inmerso en mi trabajo. (AB4) & \\
\hline
\end{tabular}




\begin{tabular}{|c|l|l|}
\hline 12 & Puedo continuar trabajando durante largos periodos de tiempo. (VI4) & \\
\hline 13 & Mi trabajo es retador. (DE5) & \\
\hline 14 & Me "dejo llevar" por mi trabajo. (AB5)* & \\
\hline 15 & Soy muy persistente en mi trabajo. (VI5) & \\
\hline 16 & Me es difícil "desconectarme" de mi trabajo. (AB6) & \\
\hline 17 & Incluso cuando las cosas no van bien, continúo trabajando. (VI6) & \\
\hline
\end{tabular}

